\title{
Structure and composition of titanium spark erosion powder obtained in liquid nitrogen
}

\author{
Gennady MONASTYRSKY ${ }^{1,3 *}$, Patrick OCHIN ${ }^{2}$, Guillaume Y. WANG ${ }^{2}$, Victor KOLOMYTSEV ${ }^{3}$, Yuri KOVAL ${ }^{3}$, \\ Vitaliy TINKOV ${ }^{3}$, Anatoliy SHCHERBA ${ }^{4}$, Sergey ZAHARCHENKO ${ }^{4}$ \\ ${ }^{1}$ National Technical University of Ukraine "KPI”, Peremogy Ave. 37, UA-03506 Kyiv, Ukraine \\ ${ }^{2}$ Institut de Chimie et des Matériaux Paris-Est, ICMPE-CNRS, 2-8 Rue Henri Dunant, 94320 Thiais, France \\ ${ }^{3}$ Institute of Metal Physics of NAS of Ukraine, Vernadsky Ave. 36, UA-03142, Kyiv, Ukraine \\ ${ }^{4}$ Institute of electrodynamics of NAS of Ukraine, Peremogy Ave. 56, UA-03680, Kyiv, Ukraine \\ * Corresponding author. Tel.: +380-97-4068512; fax: +380-97-4068512; e-mail: monag@imp.kiev.ua
}

Received November 17, 2010; accepted May 18, 2011; available on-line November 8, 2011

Titanium powders were obtained by the spark-erosion method in liquid nitrogen. As-processed powder particles with typical sizes between 1 and 50 microns have spherical shape. The surface of the Ti powder particles has irregular structure. Many of the micron-sized particles contain irregular holes inside. The inner surface of the holes has well arranged bubble-like structure. The chemical analysis, made by the Kjeldahl method, showed that the powder contains $11.24 \pm 0.06 \mathrm{wt}$.\% of nitrogen, while the more reliable XRD method gave 12.4 $\pm 0.2 \mathrm{wt}$.\%. Backscattering scanning electron microscopy images of cross sections of powder particles, as well as EDX analyses, showed a cellular structure of the particles with nitrogen-rich areas of several microns, separated by relatively thin boundaries of $\alpha$-Ti(N). The XRD study confirmed that the powder contains about $85 \mathrm{wt}$. $\%$ of the $\delta$-TiN ${ }_{x}$ nitride (osbornite, $\left.\mathrm{Fm}-3 \mathrm{~m}\right), 10 \mathrm{wt}$. \% of $\alpha$-Ti(N) $\left(\mathrm{Pb}_{3} / \mathrm{mmc}\right)$ and minor quantities of $\alpha$ - and $\beta$-Ti (no more than $4 \%$ in total). The TEM investigation showed that particles with sizes between 10 and $100 \mathrm{~nm}$ are mainly $\delta$-TiN $N_{x}$ nitride, although the quantity of oxygen in the nanoparticles is high. The proposed model for solidification of Ti powder particles considers multiple formation of nuclei of the solid phase on the surface of liquid droplets. It makes it possible to estimate, on the one hand the upper and lower temperatures of the molten droplets that were reached during the spark erosion, and on the other hand the cooling rate, and eventually to specify the mechanism of pore formation inside the powder particles.

Powder / Spark-erosion method / Ti-N / Titanium nitride

\section{Introduction}

The spark erosion method is a promising method of obtaining powders of metals and alloys. This method can produce powders in a wide range of sizes from a few tens of $\mathrm{nm}$ to several tens of microns [1-6], depending on the state (gaseous, liquid or solid) from which the powder particles are quenched. Powders of pure Ni [3,4], ferromagnetic Mn-Al-C [5], Fe-Si-B, $\mathrm{Nd}-\mathrm{Fe}-\mathrm{B}$ [6,7], Co50-Fe50 [8], $\mathrm{Ni}_{3} \mathrm{Fe}$ [18], giant magnetostrictive alloy Fe83-Ga17 [4,11, Refs. in 6], W, Ta, Fe, Ti carbides [9, Refs. in 6], Ni-Mn-Ga [1,10], Ti-Ni-Cu, Ti-Ni-Cu-Zr [1,2,12-16], Ni-Al [2] and $\mathrm{Ti}-\mathrm{Ni}$-Hf [16] shape memory alloys, $\mathrm{MgO}$ oxide [18], different types of Fe nitride [19], U-Mo [20], the Ni-based superalloy René 95 [21] and Ti-Zr-Ni hydrogen storage alloys [22] have already been produced by this method. In the case when a cryogenic liquid is used $[1-4,10,14,15]$ the average compositions of the powders are very close to those of their respective initial master alloys. This is a significant advantage for obtaining the powders of alloys, the functional properties of which are strongly dependent on the alloying component (shape memory alloys, magnetic shape memory alloys). The $\mathrm{Ni}-\mathrm{Mn}-\mathrm{Ga}$ powders produced in liquid nitrogen were practically free from contaminations [1], whilst traces of $\mathrm{Ti}-\mathrm{N}$ were found in $\mathrm{Ti}-\mathrm{Ni}-\mathrm{Cu}-\mathrm{Zr}$ powders $[13,15]$. It is well known that both $\mathrm{Ti}$ and $\mathrm{Zr}$ form stable compounds with nitrogen. Although the use of liquid argon looks more attractive if the alloy contains $\mathrm{Ti}$ or $\mathrm{Zr}$, the mechanism and scenario of Ti-N formation during spark erosion processing needs clarification.

Despite the successful application of the spark erosion method for powder production, some issues require more detailed consideration. The temperature to which the material is heated due to the spark electric discharge, and the heating rate can be evaluated by estimating the mass balance of the formed powder and the power of the discharge. These 
parameters have been experimentally determined $[3,6,13]$; the estimated temperature in the spark may reach $10^{4} \mathrm{~K}$, the heating rate $10^{9} \mathrm{~K} / \mathrm{s}$. An experimental determination of the cooling rate of the particles has not yet been performed and the theoretical evaluation is difficult due to the lack of clear understanding of the mechanisms of powder formation from the gaseous and liquid state. Currently there are few experimental estimations of the quenching rate that is realized in this method. It is between $5 \times 10^{5}$ and $5 \times 10^{7} \mathrm{~K} / \mathrm{s}$, depending on which dielectric liquid was used [21].

So far little attention has been paid to the estimation of the relative parts of the powder that originate from the gaseous and liquid states during spark erosion processing. Morphological features can successfully distinguish the so-called mechanical powder fraction from those that form from the liquid and gaseous phases, which is especially clearly seen in the case of Ni-Mn-Ga [10]. The spherical shape of both the "gaseous" and "liquid" fractions of the powders does not allow a separation using this feature. Obviously, a correct evaluation of the quenching rate and the relative parts of different fractions of powder will contribute to the comprehension of the mechanisms of powder formation. It is also important to estimate the practical potential of the spark erosion method for obtaining nanosized powders and powders of materials with high ability to amorphization.

Titanium was selected as model material for several reasons. A) The Ti-N system is well studied, at least under equilibrium conditions. This makes it possible to assume the composition and structure of the phases formed by the interaction of titanium with nitrogen in the process of spark erosion, and determine the quantities of powders that have formed from the gas, liquid and solid states. Although these parameters are rather a technological issue, the correct determination of them would allow constructing a model for rapid quenching of liquid titanium droplets into liquid nitrogen during the spark erosion process and evaluating the rate of quenching in situ as well as the maximum and minimum temperatures of these droplets. B) The understanding of the behavior of titanium under non-equilibrium conditions is important because it is the basis of many alloys, the functional properties of which strongly depend on the composition and the methods of their preparation, including various methods of rapid solidification. On the other hand one can assume that the behavior of vapor/liquid Ti during the spark erosion processing should be similar to the behavior typical of the gas atomization method under comparable conditions. C) Comparison of the properties of the spark erosion powder with those obtained by other methods to produce TiN powder [52-55] is by itself of sufficient interest.

The main goal of this work was to clarify the mechanisms of formation of the structure and composition of titanium powder during rapid quenching into liquid nitrogen based on experimental data of the structure, composition and morphological features of Ti-N particles obtained by the spark erosion method.

\section{Experimental}

The general principle of spark-erosion processing was described in details in $[3,6,17,21]$ and involves the application of a heavy current between two electrodes and a lot of pieces (chunks) prepared from the prealloyed material, both being immersed in a dielectric refrigerant inside a container. The key idea of the method is the melting (evaporation) of the material by an electric discharge with a duration of 5-100 $\mu$ s with subsequent quenching of the molten droplets in situ into liquid nitrogen (Fig. 1).

In this work granules with a typical size of 3-6 mm of spongy titanium (TG-110) was used for powder production. Two rectangular electrodes of $100 \times 24 \times 6 \mathrm{~mm}^{3}$ were prepared from the alloy VT- 16 . The chemical composition of the raw materials is presented in Table 1. The peak voltage and peak current of the impulse of the electric discharge were about 225-240 V and 1560-1890 A, respectively. The discharge pulse duration was about $80 \mu$ s. After the spark erosion treatment of $110 \mathrm{~g}$ of granules of spongy titanium in liquid nitrogen $70 \mathrm{~g}$ of powder was obtained. In order to prevent possible explosion of the finest particles the powder was kept in a vessel with liquid nitrogen during the day until all the nitrogen had evaporated. The powder was sieved and divided into three fractions: more than $65 \mu \mathrm{m}$, less than 65 and more than $32 \mu \mathrm{m}$, and less than $32 \mu \mathrm{m}$.

The XRD structure study was performed at room temperature by the Debye-Scherrer method with $\mathrm{Co} \mathrm{K} \alpha_{1,2}$ radiation. Equipments with different resolution were used. The diffractometers DRON-3M and D-5000 SIEMENS were used for full range scanning. The instrument Philips PW1830 with the Multi-Purpose X-ray Diffraction System from PANalytical, which implements real time multiple strip X-ray detection technology, was used for highresolution scanning of overlapping $\alpha$-Ti and $\alpha-\mathrm{Ti}(\mathrm{N})$ peaks. Quantitative phase analysis was performed by the method of successive approximations using the shareware software MAUD. Firstly the basic instrumental and structural parameters were tuned: scale factor, background parameters, Caglioti coefficients [56]. Then the lattice parameters and volume fractions of the different phases in the powder were modified. After that the Debye-Waller factors and occupation numbers $(\mathrm{ON})$ of the atom sites in each of the structures were modified additionally. Finally the microstructure parameters were tuned: grain size, crystallite size (coherent scattering volume) and isotropic microdeformation of each phase. It should be noted that the latter options only slightly influenced the volume fraction of each phase, the 
Table 1 Composition of the raw materials (wt.\%).

\begin{tabular}{c|c|c|c|c|c|c|c|c|c|c|c}
\hline Material/Element & $\mathrm{Ti}$ & $\mathrm{N}$ & $\mathrm{Al}$ & $\mathrm{Mo}$ & $\mathrm{V}$ & $\mathrm{Fe}$ & $\mathrm{C}$ & $\mathrm{Si}$ & $\mathrm{Ni}$ & $\mathrm{O}$ & $\mathrm{Cl}$ \\
\hline TG-110 (nominal) & 99.65 & $<0.02$ & & & & $<0.09$ & $<0.03$ & $<0.03$ & $<0.05$ & $<0.05$ & $<0.08$ \\
VT-16 (measured) & $88 \pm 0.2$ & & $2.2 \pm 0.4$ & $5.2 \pm 0.2$ & $4.6 \pm 0.2$ & & & & & & \\
\hline
\end{tabular}

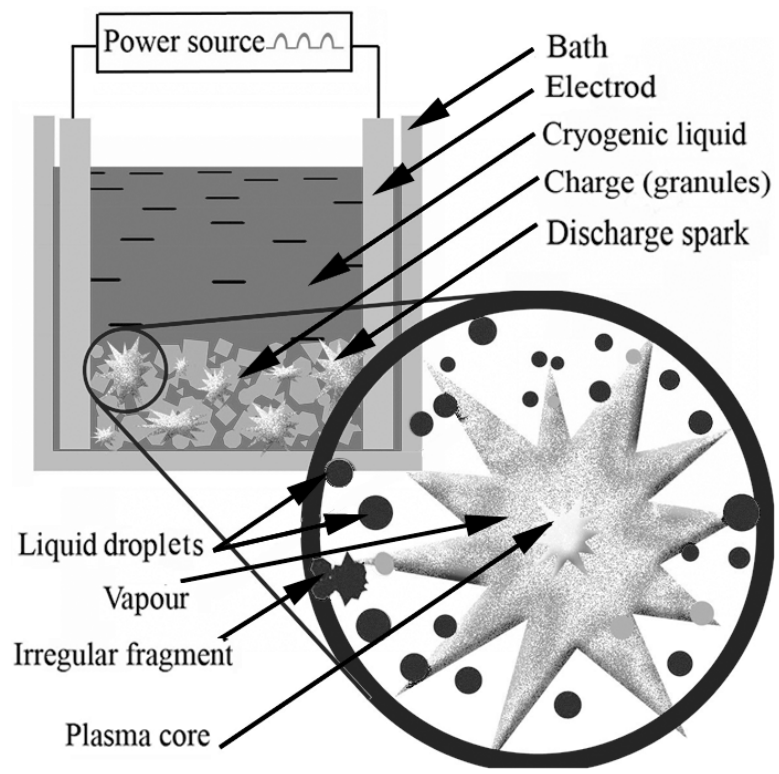

Fig. 1 A schematic illustration of the spark erosion process.

composition and lattice parameters confirmed that the previous steps had been executed properly. Finally all of the parameters, except the microstructural ones, were refined simultaneously.

The total content of metal elements in the powder and electrodes was determined by the integrated EDX method. The integrated nitrogen content in the powder was determined by the modified Kjeldahl method, the digestion procedure of which consists of several hour dissolution of a 0.3 to $0.6 \mathrm{~g}$ powder in a mixture of phosphoric acid and hydrofluoric acid with a little addition of hydrogen peroxide.

The TEM investigation was carried out with a high-performance analytical microscope Tecnai ${ }^{\mathrm{TM}} \mathrm{G} 2$ F20. For the sample preparation the powder was mixed with ethanol, the mixture was dropped onto a copper grid covered by carbon film. After evaporation of the ethanol (approximately $1 \mathrm{~min}$ ) the sample was placed in the column of the microscope.

The powder particle morphology was studied by SEM. A Hitachi S-2500 device was used only for the morphological study of the particles. In order to study the internal structure and composition of particles larger than $2 \mu \mathrm{m}$, the powder was mixed in a resin. The mixture was polished after hardening. The crosssection of the particles and their composition were analyzed by a LEO 1530 instrument equipped with a PGT PRISM 2000 (Ge) spectrometer without reference standards. The nitrogen content obtained this way was dramatically small (about 3 wt.\%).
An average nitrogen content in the powder closer to that obtained by the XRD and Kjeldahl methods was shown by a JSM-6490LV (Jeol) device equipped with an Energy Dispersive spectrometer (EDS) INCA Energy 450 (Oxford Instruments). A cobalt reference was used to fit a comprehensive library of line profiles to the acquired spectrum. However this result could not be considered as completely reliable due to significant overlapping of titanium and nitrogen $\mathrm{K}$ peaks. Therefore the WD spectrometer of the JSM6490LV instrument with higher energy resolution was employed. Only local point chemical analysis of individual particles was performed because this spectrometer is not able to acquire a spectrum from a rectangular region.

\section{Results}

i. SEM investigation: morphology and chemical composition of micron-sized particles

The SEM investigations confirmed that the powder consists of three typical fractions (Fig. 2a,b). The particles beyond about $100 \mu \mathrm{m}$ are formed by the cracking of granules due to electro-mechanical impacts and have irregular shape. This part of the powder, being a residue, will not be taken into consideration because it has not partaken in the process of arc-melting followed by quenching in liquid nitrogen. The particles that formed due to quenching from the liquid phase have close to spherical shape with dimensions of several microns to tens of microns (Fig. 3a). In most cases, these particles are coated by the fine spherical particles with dimensions of several tens of nanometers to 1 micron (Fig. 3b). This fraction forms conglomerates with sizes up to several tens of microns.

Typical metallographic cross sections of particles are shown in Fig. 2b. Many particles have hollows inside (Fig. 4a,b). The inner surface of the large pores consists of globular, oblong formations with size 1-2 $\mu \mathrm{m}$. In some cases these formations have fairly regular shape (Fig. 4b). The outer surface of such particles shows an uneven relief (Fig. 4a,b). Other particles have a spherical shape. Theirs surface is similar to solidified lava (Fig. 3a,b). The enlarged image shows that the entire surface is covered by separate islands-drops of smooth irregular shape with sizes from 20 to $500 \mathrm{~nm}$ (Fig. 5a). Here and there this region shows a banded structure, resembling fine twins or martensite (Fig. 5b). Many of these drops have small holes. Such a surface structure differs drastically from that observed in particles formed from 

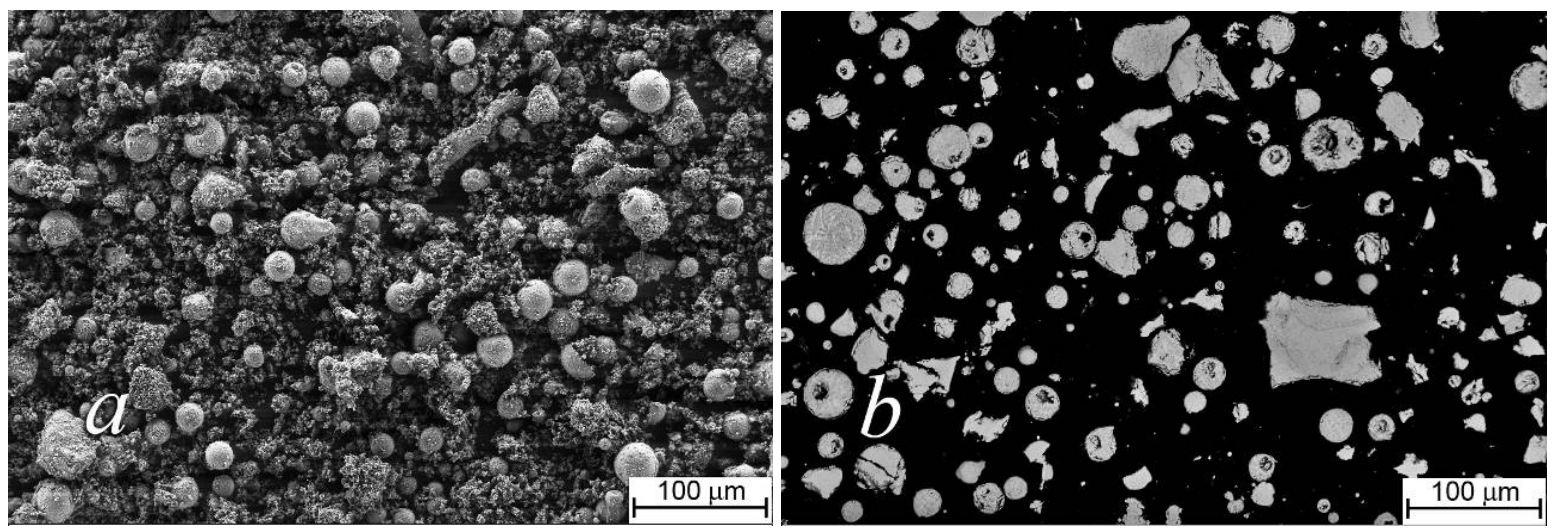

Fig. 2 Morphology of a spark erosion Ti powder obtained in liquid nitrogen: a) SEM image of as-processed powder; $b$ ) BSE image of the cross-sections of particles.
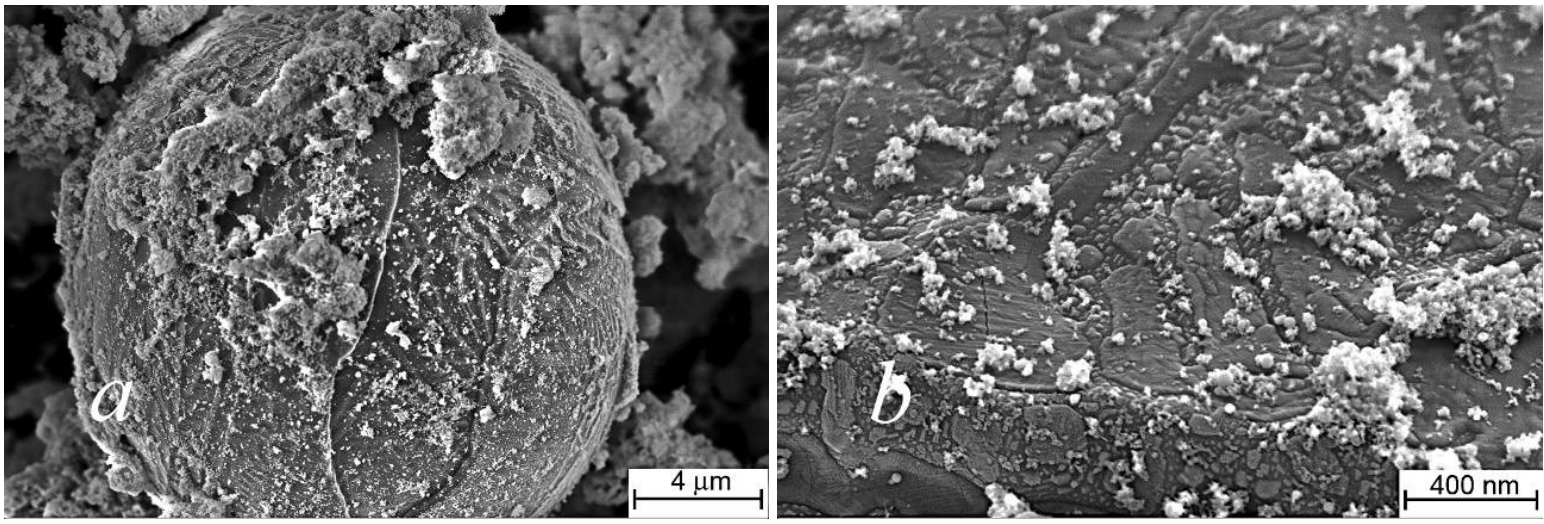

Fig. 3 Micron-sized particles: a) SEM image of a particle covered by conglomerates of nanosized particles; b) SEM image of the surface relief of a micron-sized particle.
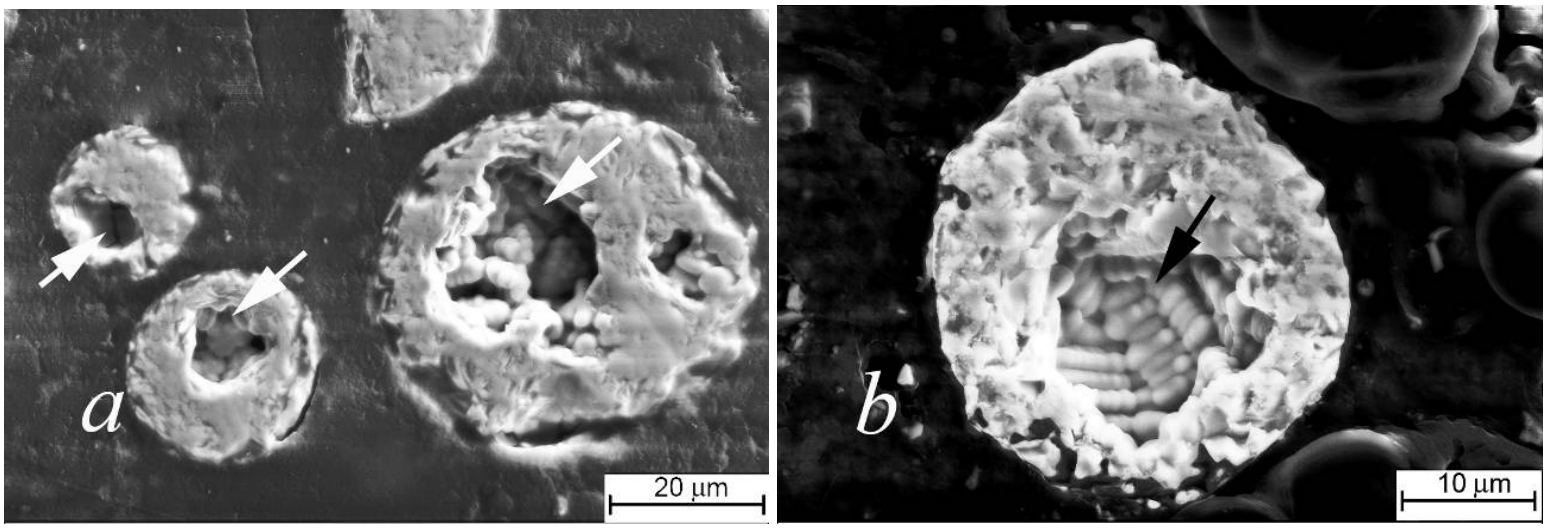

Fig. 4 Pores inside micron-sized particles: a) SEM image of the cross-section of particles with irregular surface; arrows indicate the pores; $b$ ) SEM image of the cross-section of particles with fairly regular formations inside the pore, indicated by an arrow.

the liquid phase and quenched in liquid argon $[1,2,13,14]$. Hollow particles seem to be a very typical morphology of spark erosion powders obtained in liquid nitrogen $[1,4]$, although such peculiarities have been observed for powders obtained in ethanol too [12].
It was established that the inner structure of the particles is cellular. Rounded cells, $1-5 \mu \mathrm{m}$ large, enriched by nitrogen (dark areas in Fig. 6a) are separated from one another by thin layers (less than 1-2 $\mu \mathrm{m})$ with reduced nitrogen content (light areas in Fig. 6a). This cross-section is similar to that described 

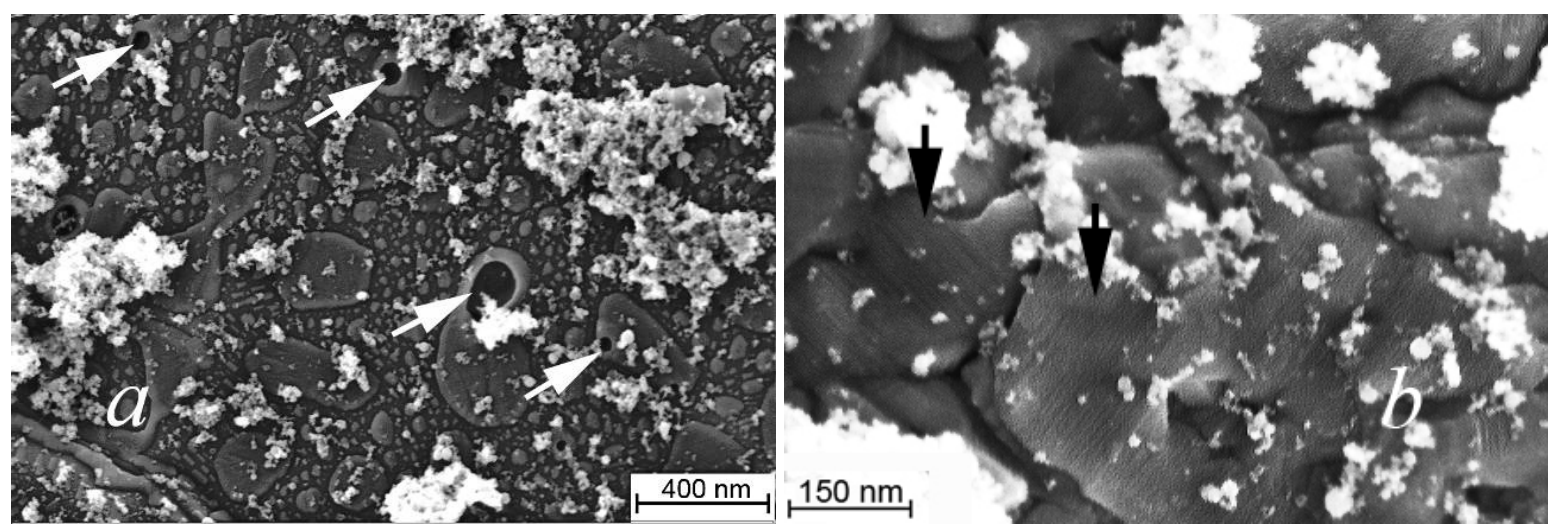

Fig. 5 Enlarged view of the surface of micron-sized particles: $a$ ) island-drops with holes on the surface (SEM image); arrows indicate the holes; $b$ ) banded structure on the surface.
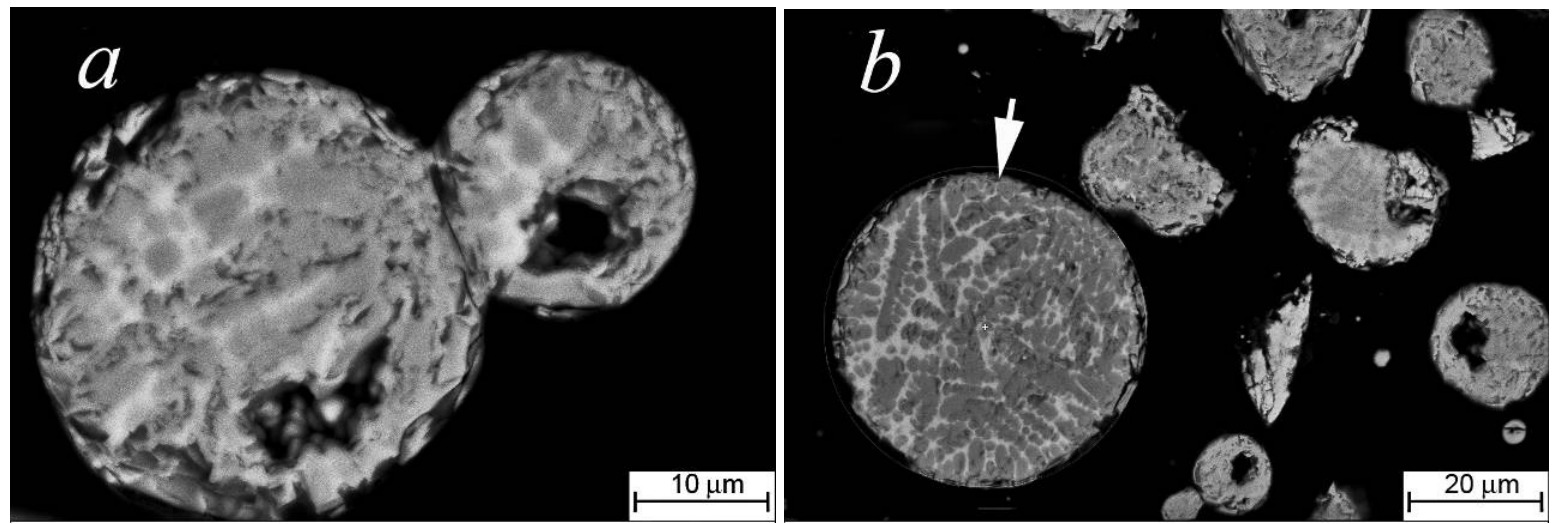

Fig. 6 Composition segregation in micron-sized particles: a) BSE image of the cross-section of particles showing redistribution of nitrogen inside the powder particles (cellular structure); $b$ ) BSE image of the crosssection of particles having distinct dendrite morphology, indicated by an arrow.

Table 2 Results of the local chemical analysis of the powder composition performed with a WD spectrometer.

\begin{tabular}{l|c|c|c|c|c}
\hline \multicolumn{1}{c|}{ AOI /Element } & $\mathrm{Ti}$ & $\mathrm{N}$ & $\mathrm{V}$ & $\mathrm{Mo}$ & $\mathrm{Al}$ \\
\hline Dark area, at.\% & $50.2 \pm 2.3$ & $48.5 \pm 2.4$ & $1.3 \pm 0.2$ & - & - \\
Light area, at.\% & $65.0 \pm 1.4$ & $35.0 \pm 1.4$ & - & - & - \\
Average (estimation), at.\% & $52.1 \pm 4.2$ & $46.8 \pm 4.5$ & $1.1 \pm 0.2$ & - & - \\
"Electrode" particles, at.\% & $54.1 \pm 0.5$ & $19.5 \pm 2.0$ & $10.0 \pm 1.1$ & $9.7 \pm 1.1$ & $6.7 \pm 0.2$ \\
\hline
\end{tabular}

by Denoirjean et al. $[23,24]$ for $\mathrm{Ti}-\mathrm{N}$ particles produced by the gas atomization method. The ratio between the areas of dark and light regions has approximately to correspond to the ratio between the amounts of phases enriched and depleted with nitrogen. This ratio, averaged over 7 images of particle cross sections, was 87:13. The weighted averages of the composition of dark and light areas with factors 0.87 and 0.13 , respectively, were taken in order to estimate the average composition of the powder particles (Table 2).

One can note that the nitrogen content of the narrow light areas could be overestimated due to the signal coming from the adjacent dark areas. The main problem for accurate measurements of the titanium and nitrogen content is the deconvolution of overlapping K-lines of $\mathrm{Ti}$ and $\mathrm{N}$. In addition, according to the data of Oxford Instruments, the X-ray generation volumes for $\mathrm{Ti}$ and $\mathrm{N}$ are significantly different -1.7 and $2.1 \mu \mathrm{m}$, respectively. Therefore the results of the SEM study give us only a view of the inner structure of the particles and the distribution of the elements in them, rather than the exact composition of the particles.

Finally, powder particles with a distinct dendrite cross-section were found here and there (Fig. 6b). The composition of these particles, besides $\mathrm{Ti}$ and $\mathrm{N}$, consisted also of $\mathrm{Al}, \mathrm{Mo}$, and $\mathrm{V}$. Obviously these 
Table 3 Results of the EDS analysis of the chemical composition of the nanopowder.

\begin{tabular}{l|c|c|c|c|c|c|c}
\hline \multicolumn{1}{c|}{ Element(Line) } & $\mathrm{Ti}(K)$ & $\mathrm{N}(K)$ & $\mathrm{V}(K)$ & $\mathrm{Si}(K)$ & $\mathrm{Ca}(K)$ & $\mathrm{O}(K)$ & $\mathrm{C}(K)$ \\
\hline Average, at.\% & 10.2 & 10.5 & 1.3 & 3.4 & 0.3 & 14.4 & 39.8 \\
E.s.d., at.\% & 4.5 & 2.1 & 0.7 & 1.8 & 0.2 & 4.3 & 12.7 \\
\hline
\end{tabular}

particles come from the electrodes, which contain the elements mentioned above. Results of the local spectral analysis of the powder particles are listed in Table 2.

ii. TEM investigation: morphology and chemical composition of nano-sized particles

The TEM investigation revealed that the finest particles with dimension down to $10 \mathrm{~nm}$ have a trend to form conglomerates (Fig. 7). The dominating particle morphology is spherical although somewhere cuboids were found, which is typical of ultrafine $\delta$-TiN $x$ particles $[25,26]$ as well as of $\delta$-TiN $x$ clusters [27]. The electron diffraction patterns consist of diffuse rings and distinct spots (inset of Fig. 7) related to the strictly crystalline structure. The former and latter ones belong to the cubic $(F m-3 m)$ titanium nitride phase (osbornite). The lattice parameter calculated from the diffraction is $a=4.19 \pm 0.03 \AA$, which is closer to $\mathrm{TiO}$ than to TiN. It seems as if the rings correspond to nanosized particles and the distinct spots to submicron ones. Several weak spots inside the (111) ring may belong to unidentified oxides.

The EDS analysis of several agglomerates of fine particles gave to some extent contradictory results. One can assume that the finest particles are titanium nitride as far as the atomic percent of titanium is equal to the atomic percent of nitrogen in average (see Table 3). However silicon, calcium, oxygen, and carbon were found in the samples. Carbon seems to appear due to the carbon film, which was used as substrate. The signal measured from the carbon film was about 2200 counts, while that from the agglomerates situated on the film is $2500-4500$. The presence of silicon, calcium and some amounts of oxygen could be explained by contamination by $\mathrm{SiO}_{2}$ coming from the vessel where the powder was kept. It is well known that the hardness of $\delta$-TiN ${ }_{x}$ is very high and the powder particles can scratch slightly the glass and produce $\mathrm{SiO}_{2}$ in such a way. However, even if taking into account such an explanation, almost 8 at.\% of the oxygen is left free. It can be present in some fixed form, for instance in the remains of ethanol. The EDS analysis is not suitable to determine the hydrogen content, while carbon is masked by the carbon of the substrate. Another suitable explanation is that some of the particles are $\mathrm{TiO}$, which has formed due to reaction of ultrafine Ti particles with residuel oxygen present in the liquid nitrogen. It is very feasible that each of the agglomerates is a mixture of $\delta-\mathrm{TiN}_{x}$ nitride and $\mathrm{TiO}$ oxide.

\section{iii. Total chemical composition of the powder}

Part of the powder, which came from the electrodes, was determined by measuring the decrease of the weight of the electrodes after the spark erosion treatment and was about $4.1 \%$ of the total quantity of collected powder. The composition of the electrodes was Ti88-A12.2-Mo5.2-V4.6 wt.\%. Consequently the content of Mo, $\mathrm{V}$, and $\mathrm{Al}$ in the powder, which could come from the electrodes made from VT-16, does not exceed 0.2 wt. $\%$ for each of the elements. Therefore the impurities Mo, V, or Al were not detected by the integral EDX spectral analysis. The total nitrogen content in the powder, found by the Kjeldahl method, was $11.24 \pm 0.06 \mathrm{wt} . \% \quad(30.23$ at.\%), that is significantly less than $22.60 \mathrm{wt} \% \quad$ (50 at.\%) for equiatomic titanium nitride.

\section{iv. XRD study}

Analysis of XRD patterns obtained with the aid of diffractometers SIEMENS D-5000 and DRON-3M showed that the phases contained in the powder have

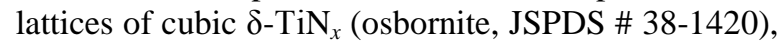
solid solution of nitrogen in $\alpha-\operatorname{Ti}(\mathrm{N}) \quad\left(\alpha-\mathrm{Ti}_{0.30}\right.$, JSPDS \#41-1352) and $\alpha$-Ti. In addition $\beta$-Ti phase was found in the powder after more detailed studies carried out with a Philips PW1830. A typical XRD pattern of a powder with a grain size of less than 32 microns recorded by this instrument is shown on Fig. 8. Significant differences between the patterns obtained from powders of various fractions were not detected. A possible reason is that the contributions of nanosized particles to XRD patterns is relatively small compared to those of micron-sized particles. Another explanation is that the part of agglomerated nanoparticles is practically the same in all the fractions.

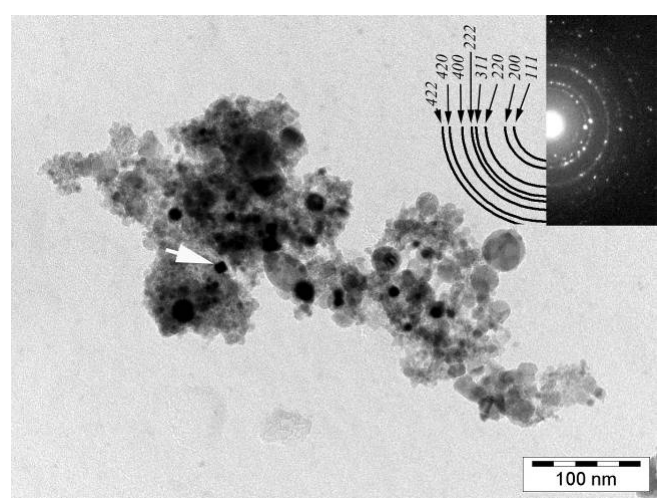

Fig. 7 Morphology of nanosized $\mathrm{Ti}$ powder obtained in liquid nitrogen. The arrow indicates cuboid particle morphology. The inset shows the diffraction pattern. 
Table 4 Results of the fitting of XRD data for spark erosion Ti powder obtained in liquid nitrogen. $O N_{N}$ - occupation number of the nitrogen sites; $X_{N}$ - atomic content of nitrogen in the corresponding phase calculated from different experimental data; $C_{p h}$ - volume fraction of the corresponding phase in the powder; $C_{N}$ - nitrogen content in the powder; I - values determined from the occupation number of the $\mathrm{N}$ site; II - values determined from the lattice parameters.

\begin{tabular}{|c|c|c|c|c|c|c|c|c|c|c|c|}
\hline Phase & $\begin{array}{l}\text { Space } \\
\text { group }\end{array}$ & $\begin{array}{l}a, \\
\AA\end{array}$ & $\begin{array}{l}c, \\
\AA\end{array}$ & $O N_{N}$ & $\begin{array}{c}X_{N}, \\
\text { at.\% } \\
\text { I }\end{array}$ & $\begin{array}{c}X_{N}, \\
\text { at.\% } \\
\text { II }\end{array}$ & $\begin{array}{c}X_{N}, \\
\text { at.\% } \\
\text { II-a }\end{array}$ & $\begin{array}{c}X_{N}, \\
\text { at. } \% \\
\text { II-c }\end{array}$ & $\begin{array}{l}C_{p h}, \\
\text { wt. } \%\end{array}$ & $\begin{array}{c}C_{N}, \\
\text { wt.\% }\end{array}$ & $\begin{array}{l}C_{N}, \\
\text { at.\% }\end{array}$ \\
\hline$\delta-\mathrm{TiN}_{x}$ & $F m-3 m$ & $4.2182_{4}$ & - & $0.6_{1}$ & 37.9 & $35.5_{2}$ & - & - & 85.6 & $13.3(I)$ & 34.4 \\
\hline$\alpha-\operatorname{Ti}(\mathrm{N})$ & $P 6_{3} / m m c$ & $2.9705_{4}$ & $4.7701_{7}$ & $0.0_{3} \div 0.2_{5}$ & $0.0_{3} \div 0.2_{0}$ & - & $18.3_{4}$ & $13.1_{2}$ & 10.0 & $12.5(I I-a)$ & 32.8 \\
\hline$\alpha-\mathrm{Ti}$ & $\mathrm{PG}_{3} / \mathrm{mmc}$ & $2.956_{8}$ & $4.687_{1}$ & - & 0 & - & - & - & 3.5 & $12.3(I I-c)$ & 32.4 \\
\hline$\beta-\mathrm{Ti}$ & Im-3m & $3.296_{6}$ & - & - & 0 & - & - & - & $0.8_{8}$ & $\begin{array}{c}11.2_{4} \\
\text { (Kjeldahl) }\end{array}$ & $30.1_{3}$ \\
\hline
\end{tabular}

Fitting of the XRD data gave the volume fractions of the different phases, the occupation number for each of the elements and the lattice parameters. In turn these data allowed calculating the total content of nitrogen from the occupation numbers of the nitrogen sites in $\delta$-TiN ${ }_{x}$ and $\alpha$-Ti(N) (method I, see Table 4). The refinement procedure showed a large discrepancy of occupation numbers of nitrogen for the $\alpha-\operatorname{Ti}(\mathrm{N})$ phase depending on the different parameters of the procedure and their initial values.

A more precise estimation was obtained from the lattice parameters. The value of the lattice parameter of $\delta-\mathrm{TiN}_{x}$ gives an indication about the mean stoichiometry of the phase since it varies with the quantity of nitrogen according to the equation $a=4.1925+0.0467 x \AA$ [28]. The value of $a=4.2182_{4}$ gives $x=0.55$ (method II), which is close to the occupation number of the nitrogen site of $\delta$-TiN ${ }_{x}$ FCC lattice, obtained from the fitting procedure (0.61). The variation of the lattice parameters $a$ and $c$ are also approximately linear functions of the nitrogen content in the $\alpha-\operatorname{Ti}(\mathrm{N})$ solid solutions. According to [29] the expression for $a=2.961+0.00052 x$ gives the nitrogen content in $\alpha-\mathrm{Ti}(\mathrm{N})$ solid solution as 18.3 at.\% (method II-a) while the expression for $c=4.74+0.0023 x$ gives 13.1 at.\% (method II-c). A final refinement with preset nitrogen contents (calculated from the lattice parameters dependences) returned the total nitrogen content as well as the volume fraction of each phase. The nitrogen content of $\delta-\mathrm{TiN}_{x}$ was determined by method II, whereas the determination of nitrogen content in $\alpha-\operatorname{Ti}(\mathrm{N})$ by means of method II-a and method II-c returned a slightly different total content of nitrogen in the powder (Table 4).

\section{Discussion}

\section{i. Quantitative phase analysis}

The total content of nitrogen calculated from the XRD data was only about one weight percent more than that determined by the Kjeldahl method, while the SEM results differed significantly. In the latter case, taking the total amount of $\delta-\mathrm{TiN}_{x}$ and $\alpha-\mathrm{Ti}(\mathrm{N})$ phases as at least $95 \%$ (see Table 4) and assuming that the average composition of the particles is close to equiatomic TiN (see Table 3), the total amount of nitrogen was evaluated to at least $21 \mathrm{wt} . \%$. Consequently the powder should be made almost exclusively of titanium nitride with a golden color characteristic of TiN [30,57], which was in fact not observed. In addition even the light areas on the SEM images had the composition, corresponding to osbornite or $\varepsilon$-phase (see the Ti-N phase diagram on Fig. 8). However the presence of a solid solution of nitrogen in $\alpha$-Ti was well proved by the XRD study. Thus the content of nitrogen in such areas should be less than 20.7 at.\% (see the Ti-N phase diagram), that is closer to the 13-18 at.\% evaluated from the XRD data. Similar results were obtained in $[54,55]$ for $\mathrm{Ti}$ powder synthesized by the spark discharge method in liquid ammonia. The authors claimed that titanium nitride possessing nitrogen defects $\operatorname{TiN}_{1-x}(x \sim 0.5)$ was the main product together with small amounts of $\alpha$-Ti alloyed with nitrogen. In addition there exist numerous communications, which claim that the congruent melting of $\delta$-TiN $\mathrm{T}_{x}$ corresponds to a fixed composition of about $\mathrm{TiN}_{0.8}$ rather than $\mathrm{TiN}$ [31]. It is also known that commercial titanium nitride has the composition $\mathrm{TiN}_{0.794}$ [33]. It is very hard to obtain compositions with a larger amount of nitrogen because the extra nitrogen is lost during the melting.

The Kjeldahl method was developed for determining the nitrogen content in organic substances [58], but the modified method is applicable to alloys and is usually regarded as more reliable and precise than other techniques [59]. The accuracy of the method depends on the complete dissolution of the Ti-N powder in the mixture of acids in the course of the digestion procedure. It may give an underestimated content of nitrogen since eventually not all nitrogen from the Ti-N powder can convert into ammonium acid sulfate.

Taking altogether these speculations one can conclude that the composition and phase content of the powder are more reliable when evaluated by XRD data and the powder contains $12.4 \pm 0.2 \mathrm{wt} \%$ or 


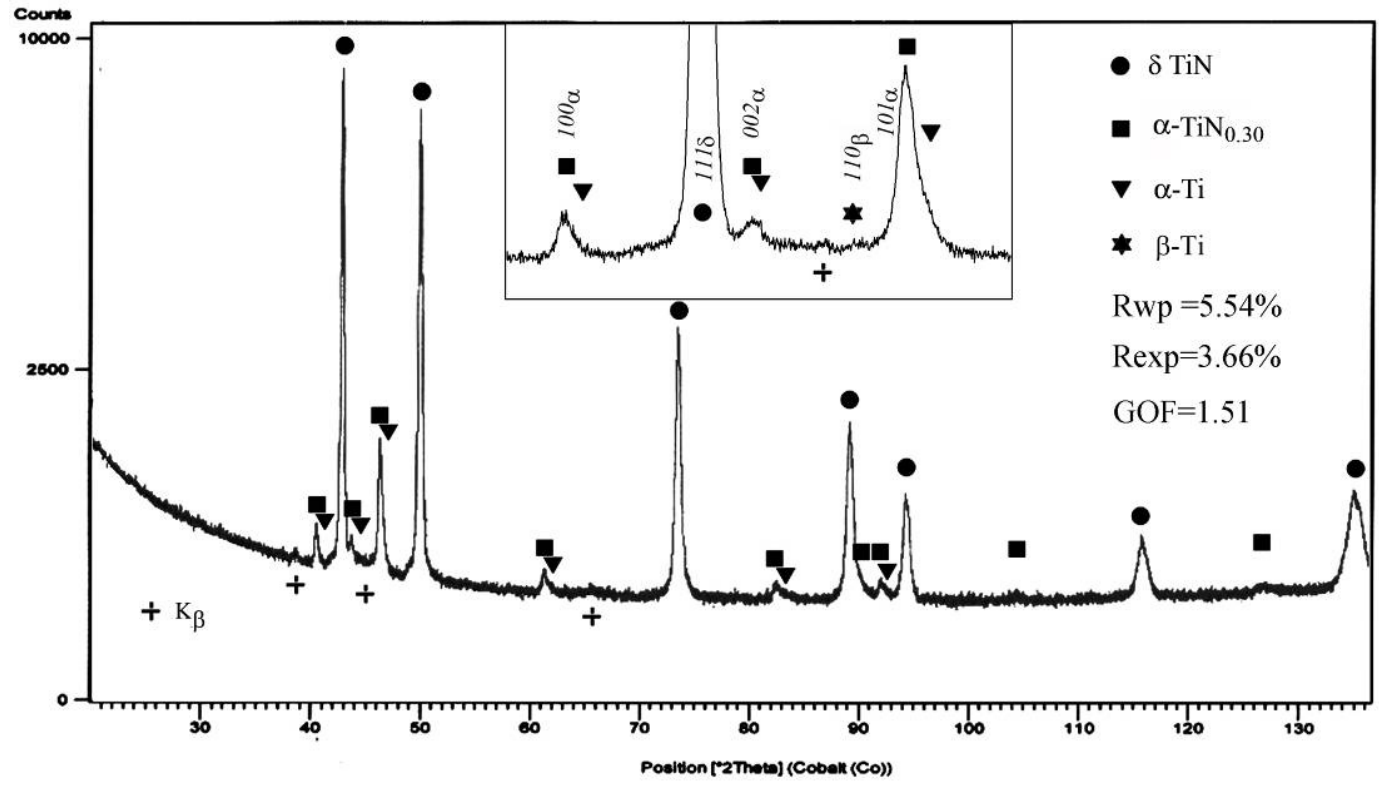

Fig. 8 Typical XRD pattern of a Ti-N powder with grain size less than 32 microns. The inset shows an enlargement of the pattern between $40^{\circ}$ and $48^{\circ}$. Weak peaks indicated by crosses are attributed to unfiltered residues of the $\mathrm{CoK}_{\beta}$ line corresponding to the strong $(111)_{\delta},(200)_{\delta}$ and $(220)_{\delta}$ peaks. GOF is the goodness of fit.

$32.6 \pm 0.4$ at. $\%$ of nitrogen. It should be noted that the discrepancy between XRD and the Kjeldahl method result was just $1 \mathrm{wt} . \%$. These results correlate well with the composition of Ti powders obtained in liquid nitrogen [52].

\section{ii. Estimation of the amounts of the different fractions of powder}

The amount of mechanical fraction is defined by the quantity of $\alpha$-Ti and consists of $3.5 \mathrm{wt} . \%$. Indeed, the process of gaseous nitriding of $\alpha$-Ti is controlled by the volumic diffusion [34,37]. It is very slow in comparison with the nitriding of liquid Ti. The structure of non molten broken pieces of $\mathrm{Ti}$ remains consistent and $\alpha$-Ti can be attributed to this fraction of powder.

$\beta$-Ti may originate from electrodes made from the $(\alpha+\beta)$ alloy VT-16. The quantitative phase analysis of XRD data obtained from the electrodes confirmed that the alloy contains $55 \pm 3$ wt. $\% \beta$-phase. Taking into account that $4.1 \mathrm{wt} . \%$ of the powder originates from the electrodes one can expect that $4.1 \times 0.55=2.3 \mathrm{wt} \%$ of $\beta$-phase should be present in the powder. The difference between the expected and measured values (see Table 4) indicates that molten droplets originating from the electrodes have reacted with nitrogen producing a redistribution between the amounts of $\alpha$ and $\beta$ phases. The relations between $\alpha$ and $\beta$ phases are defined by the processes of nitriding of the VT-16 alloy and is the matter of a separate investigation.

Results of SEM, TEM and XRD investigations have proved that the total amount of $\delta$-TiN $x$ attributes to both micron-sized particles and nanosized fraction.
The contribution of $\delta$-TiN $x$ originating from the micron-sized fraction could be evaluated from the ratio between light and dark areas on the SEM images $(13: 87 \pm 10 \%)$. Considering 10.0 wt. $\%$ of $\alpha-\mathrm{Ti}(\mathrm{N})$ (Table 4) identified as the light phase on the cross section SEM image, one can evaluate the amount of the dark phase enriched by nitrogen $\left(\delta-\mathrm{TiN}_{x}\right)$ to $10.0 \times 87 / 13=67 \pm 10 \mathrm{wt} . \%$. The nanosized fraction of the powder contributes the remaining $19 \mathrm{wt} . \%$ of $\delta$ - $\mathrm{TiN}_{x}$ approximately.

Thus taking into account the uncertainties of all measured values, which were employed for the evaluations, the amounts of different fractions are: the

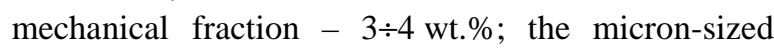
particles formed from the liquid state $-77 \pm 10 \mathrm{wt} \%$; the nanosized particles formed from the vapor state $19 \pm 10$ wt. $\%$..

\section{iii. Temperature behavior of the Ti-N particles}

One can estimate the temperature of the molten droplets, as well as the cooling rate which is reached during the quenching in liquid nitrogen in situ, using the assessed data of the Ti-N system, in particularly the Ti-N phase diagram (Fig. 9). Both the observed structure of the particles and the total nitrogen content is a function of the temperature-time history of the particles. The key idea is to simulate a history, which provides the observed structure and nitrogen content.

The conditions of the spark erosion process are very similar to the conditions of the atomization process and so is the microstructure of the particles obtained by any of these techniques. Keeping that in mind, one can expect that the schematic temperature 
behavior of a spark eroded molten particle is divided into several typical sections similar to those of atomized particles [31]. There are 1) the liquid phase cooling until the recalescence arrest temperature (path I on Fig. 9); 2) the recalescence accompanying the rapid temperature increase; 3 ) the solidification of the mushy state (mixture of liquid and solid phases) with comparatively slow cooling (path II on Fig. 9); 4) peritectic solidification at constant temperature, 5) the solid state cooling (path III on Fig. 9). In case of quenching in liquid nitrogen the saturation of the titanium particles with nitrogen should be taken into account as well. Obviously the nitrogen concentration on the surface of a liquid Ti droplet is higher than in its interior and solidification has to begin from the surface. Therefore the recalescence stage (2) could be omitted from the consideration. The behavior of liquid Ti droplets (stage 1) and solidified particles (stage 5) is governed by the energy and mass balance laws with different boundary and time conditions for each of the stages. Some simplifications and presumptions concerning the physical processes dominating at each stage have to give us two different cooling rates. The cooling rate during the third and fourth stages has to be much smaller than during the preceding and successive stages because large heat is produced in the particles during the chemical reaction between $\mathrm{Ti}$ and $\mathrm{N}$ and the phase transformation.

As a first approximation, we assume that $a$ ) the temperature behavior of the droplet (particle) is caused by heat transfer from the droplet (particle) to the spherical gaseous shell surrounding it, $b$ ) the Biot number $B i \approx h d / k$ is small (here $d \approx 10^{-6} \div 10^{-4} \mathrm{~m}$ is the diameter of the particle, $h \approx K_{N} / d$ the convective heat transfer coefficient between the surface of particle and surrounding gas, $k \approx 50 \mathrm{~W} \mathrm{~m}^{-1} \mathrm{~K}^{-1}$ [38] the thermal conductivity of liquid titanium, $K_{N} \approx 0.1 \div 0.2 \mathrm{~W} \mathrm{~m}^{-1} \mathrm{~K}^{-1}$ the thermal conductivity of nitrogen gas). Hence, the temperature gradient in the particle is close to zero, $c$ ) the velocity of the particles is zero even if this is not valid for some of them; consequently the Reynolds number $R e$ is zero and the heat transfer coefficient is conditioned only by gas thermal conductivity and the diameter of the particle, d) the ratio between the thermal and mass Fourier numbers (the ratio between the thermal diffusivity and the nitrogen diffusion coefficient) of is Ti-N particle is much larger than 1 .

iv. Qualitative estimation of the nitrogen saturation in the particles of $\mathrm{Ti}-\mathrm{N}$

The condition $d$ ) means that the dissolution of nitrogen in the particles can be described by Fick's law of diffusion with a constant diffusion coefficient at a given temperature. For the sake of simplicity the temperature fall will be considered as a linear function of time during first step of cooling in liquid stage (path I on Fig. 9). The higher the temperature, the higher the diffusivity and the faster the process of saturation with nitrogen. Two opposite trends determine the nitrogen dissolution process during the solidification in mushy state. On the one hand the cooling rate decreases by at least one order of magnitude compared to the previous stage and the nitrogen dissolution must increase. On the other hand the amount of liquid fraction in the $\mathrm{Ti}$ droplet decreases rapidly with decreasing temperature. Because the nitrogen diffusion coefficient of $\delta$ - $\mathrm{TiN}_{x}$ is smaller by several orders of magnitude than the diffusion coefficient of liquid $\mathrm{Ti}$ (Fig. 10) one can expect that the nitrogen dissolution process slows down at this stage (path II on Fig. 9). In addition, when the temperature goes down, both the equilibrium nitrogen content of $\delta$ - $\mathrm{TiN}_{x}$ corresponding to the solidus, and the equilibrium nitrogen content corresponding to the liquidus, decrease (see $\mathrm{Ti}-\mathrm{N}$ phase diagram on Fig. 9). Thus the driving force for the dissolution of nitrogen diminishes. Further fall of the temperature of the particles below the peritectic temperature can give moderate gain of nitrogen during stage 5 due to the significantly lower nitrogen diffusivity in solid Ti (Fig. 10, path III on Fig. 9).

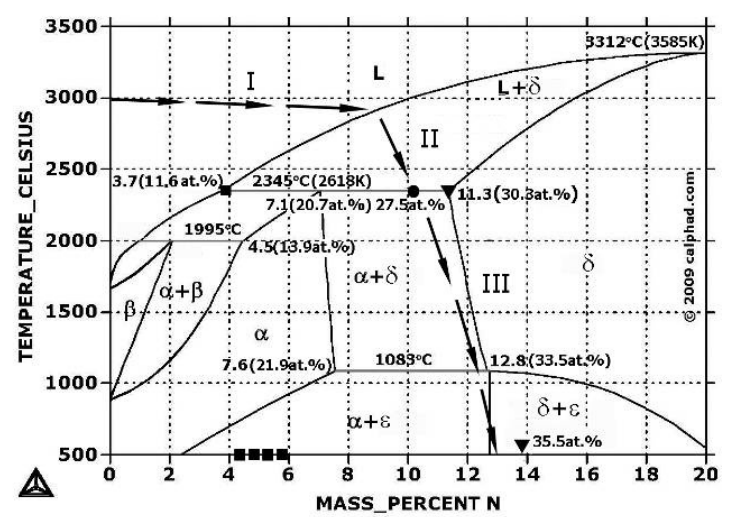

Fig. 9 Ti-N phase diagram calculated in [41]. Points that are significant for the evaluation are given in at. $\%$ and Kelvin and correlate with those given in $[32,33,42]$. Circles indicate the nitrogen concentration in the micron-sized particles, triangles - in the nitrogen-enriched phase $\left(\delta-\mathrm{TiN}_{x}\right)$, and squares - in the nitrogendepleted phase $(\alpha-\operatorname{Ti}(\mathrm{N}))$.

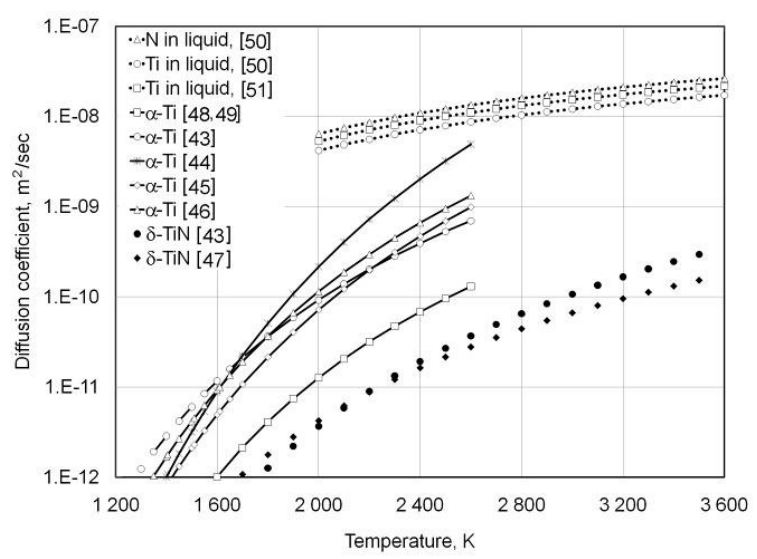

Fig. 10 Nitrogen diffusion coefficients in titanium in the different states. 
v. Cooling rate during the solid state cooling stage The total nitrogen content in as processed spark erosion powders was about 32.6 at. $\%$, which is close to $\mathrm{Ti}_{2} \mathrm{~N}$ composition according to the $\mathrm{Ti}-\mathrm{N}$ phase diagram (Fig. 9). There is a significant confusion on the formation mode of the $\varepsilon-\mathrm{Ti}_{2} \mathrm{~N}$ phase [33]. Many investigators consider that the $\varepsilon-\mathrm{Ti}_{2} \mathrm{Ni}$ phase appears according to the peritectic reaction $\delta+\alpha \rightarrow \varepsilon$, others along a congruent mode (see references in [32,33]). It can be considered as established that this phase is formed only after long-term homogenization ageing, whilst rapid quenching suppresses the formation of the $\varepsilon$ phase. As it was observed in $[34,35]$ the nonisothermal formation of the $\varepsilon$ phase is favored at the $\delta / \alpha$ boundaries. However, no evidence of even traces of this phase was found in the particles. The typical cooling rate of the quenched samples is below $10^{3} \mathrm{~K} / \mathrm{s}$. Thus one can say that the cooling rate of the particles is more than $10^{3} \mathrm{~K} / \mathrm{s}$ in the temperature interval between 500 and $1100^{\circ} \mathrm{C}$.

Another estimation could be obtained from direct gaseous nitriding data $[36,37]$. The reaction of titanium alloys with nitrogen involves the formation of a $\delta$-TiN ${ }_{x}$ layer on the surface. The diffusion of nitrogen through this superficial layer controls the mass gain per surface unit giving the parabolic kinetics in differential form [36]:

$d\left(\frac{\Delta m}{S}\right)^{2}=K d t$

The nitriding rate constant $K$ is given by the equation:

$$
K=K_{0} \exp \left(-\frac{Q}{R T}\right)
$$

where $R$ is the ideal gas constant, the activation energy $Q$ averaged for different titanium alloys is $242 \pm 15 \mathrm{~kJ} / \mathrm{mol}$ [37], the factor before the exponent $K_{0}$ is $0.5 \pm 0.4 \mathrm{~g}^{2} / \mathrm{cm}^{4} / \mathrm{s}$ [37]. For the sake of simplicity, we will consider that the cooling rate $C R_{s s}$ in the solid state is constant. Integrating Eq. 1 gives the relative mass gain for the spherical particle of the diameter $d$ caused by nitriding:

$$
\begin{aligned}
& \frac{\Delta m}{m}=\frac{3}{2 \rho d}\left(\int_{0}^{t} K_{0} \exp \left(-\frac{Q}{R\left(T_{0}-C R_{S S} t\right)}\right) d t\right)^{1 / 2}= \\
& \frac{3}{2 \rho d} \sqrt{\frac{K_{0}}{C R_{S S}}}\left(\int_{T_{0}}^{T_{f}} \exp \left(-\frac{Q}{R T}\right) d T\right)^{1 / 2} \approx \\
& \frac{3}{2 \rho d} \sqrt{\frac{K_{0}}{C R_{S S}}}\left(\int_{T_{0}}^{0} \exp \left(-\frac{Q}{R T}\right) d T\right)^{1 / 2}= \\
& \frac{3 Q}{2 R \rho d} \sqrt{\frac{K_{0}}{C R_{S S}}} \exp \left\{-\frac{Q}{2 R T_{0}}\right\}=\text { const } \cdot d^{-1} C R_{S S}^{-1 / 2}
\end{aligned}
$$

where $\rho$ is the density of the particles $\sim 4.5 \mathrm{~g} / \mathrm{cm}^{3}, T_{0}$ is the upper temperature, from which dissolution of nitrogen in $\delta$-TiN $x$ should be take into account. This temperature is determined by the temperature of the end of the previous stage - cooling in mushy state.

Two potential opportunities can be considered. If the process of nitrogen absorption in the mushy state is rather rapid, the solidification of $\delta$ - $\mathrm{TiN}_{x}$ can be completed anywhere on the solidus at a temperature corresponding to a nitrogen content higher than the equilibrium nitrogen content at the lyotectic point (30.3 at.\% on Fig. 8). If this scenario is realistic, the particles have to consist of only the $\delta$ - TiN $N_{x}$ phase and be homogeneous. Further fall of the temperature can only increase the nitrogen content, maintaining the crystal structure of $\delta$ - $\operatorname{TiN}_{x}$. However no chemically homogeneous particles were found. On the contrary, all the particles were inhomogeneous (Fig. 6a).

A more acceptable assumption is that the process of the nitrogen absorption is not so rapid and the solidification in the mushy state is not complete until the temperature reaches the peritectic line $(2618 \mathrm{~K})$. At this temperature the average nitrogen content in the particles can lie between 11.6 at.\% and 30.3 at.\% [33], being closer to 30.3 at.\% as observed for the dominating nitrogen-rich phase in the particles (Fig. 6a). One can conclude that extra nitrogen, which the particle could absorb in the solid state, is the difference between the nitrogen content in the nitrogen-rich "dark" phase (35.5 at.\% or 13.9 wt.\%, see Table 4 and Fig. 9) and the equilibrium nitrogen content of 30.3 at.\% (11.3 wt.\%) at the lyotectic point on the peritectic line, i.e. $2.6 \mathrm{wt} . \%$. Accepting the second model, setting $\Delta m / m=0.026$ and $T_{0}$ equal to the peritectic temperature in Eq. 3, one can obtain the relationship between the diameter of the particles $d[\mu \mathrm{m}]$ and the solid-state cooling rate $C R_{\mathrm{ss}}[\mathrm{K} / \mathrm{s}]$, which follows from Eq. 3:

$C R_{S S} \cong 2 \cdot 10^{7} d^{-2}$

For the particles with a diameter of $10 \mu \mathrm{m}$ the expected cooling rate is $210^{5} \mathrm{~K} / \mathrm{s}$. The dependence (Eq. 4) is due to the process of nitrogen saturation and is governed by the solid-state diffusion of nitrogen, which in turn is controlled by the heat transfer from the particle to the surrounding nitrogen gas and also has a diffusion nature.

\section{vi. Nitrogen dissolution kinetic in liquid state}

There are no direct observations of gaseous nitriding of $\mathrm{Ti}$ in the liquid state at the moment. A mathematical model was developed to estimate the nitriding of molten $\mathrm{Ti}$ droplets during quenching into liquid nitrogen. The main features of the model are the following.

A) Each of the molten droplets of radius $R_{m d}$ is surrounded by a gas nitrogen shell. The radius $R_{L N}$ of this shell can be estimated from the energy conservation law in hypothetical steady-state conditions at a given temperature $T$ :

$$
\begin{aligned}
& \lambda_{N} m_{N}+C_{p}^{N}\left(\langle T\rangle-T_{L N}\right)= \\
& C_{m d}\left(T_{\max }-T\right)
\end{aligned}
$$


where $\lambda_{N}$ is the heat of evaporation of liquid nitrogen, $m_{N}=\rho_{N} 4 / 3 \pi\left(R_{L N}^{3}-R_{m d}^{3}\right)$ is the mass of evaporated nitrogen, $C_{p}^{N}$ and $C_{m d}$ are the heat capacities of the gaseous shell and the molten droplet, calculated in the ideal gas and Dulong-Petit approximations, respectively. $T_{\max }$ and $T_{L N}$ are maximum (initial) temperature of the molten droplet and boiling point of liquid nitrogen. $\langle T\rangle=\left(T+T_{L N}\right) / 2$ is the average temperature of the gas inside the shell. It comes from Eq. 5 that $R_{L N} \gg R_{m d}$ during cooling of the molten droplet, except at the very early stage of cooling from the initial temperature $T_{\max }$ (Fig. 11). Thus it is convenient to consider that the molten droplets are quenched into cold nitrogen gas.

B) The initial velocity of each particle is very small. It means that all mechanisms of heat and mass transfer except diffusion between the molten droplet and surrounding gaseous shell are excluded. This allows us to estimate only the lower limit of the cooling rate. It is obvious that A) and B) do not take into account the dynamics of the shell and droplet or the internal movements of the gas in the shell and the asymmetry of the problem.

C) The temperature gradient inside the particle can be assumed to be very small. The ratio between the thermal and mass Fourier numbers in all the considered temperature intervals is approximately:

$$
\frac{F_{O T}}{F_{O M}}=\frac{\alpha}{D_{N, I}} \approx \frac{10^{-5}}{10^{-8}}=10^{3}
$$

where $\alpha$ is the thermal diffusivity of $\mathrm{Ti}$ alloys evaluated from [38] and $D_{N, l}$ is the coefficient of diffusion of nitrogen in liquid $\mathrm{Ti}$, which was calculated in [39] using a variational thermodynamic method as $D_{N ; l}=1.35 D_{T i, l}$, where $D_{T i ; l}$ is the self diffusion coefficient of liquid titanium (Fig. 10). According to the obtained estimation, isothermal diffusion of nitrogen takes place in the molten droplet at any temperature.

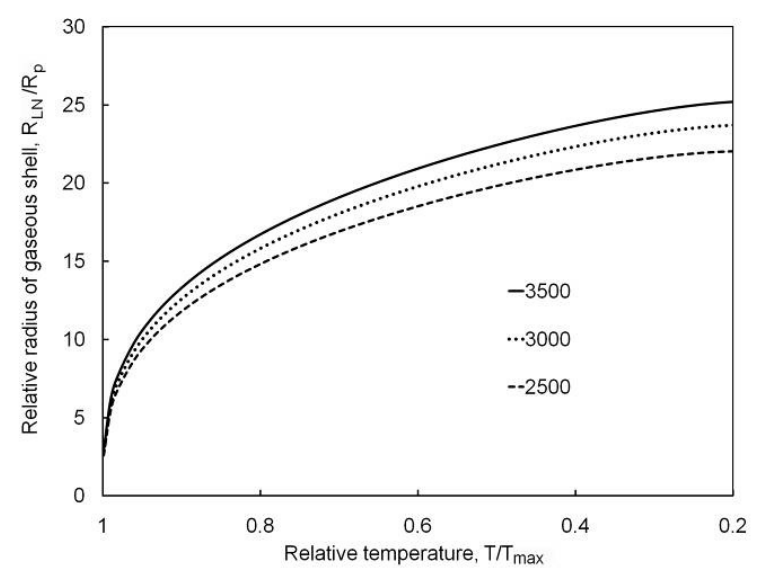

Fig. 11 Relative radius of the gaseous shell with respect to the radius of the droplet $R_{\mathrm{p}}$ as a function of the ratio $T / T_{\max }$.
D) The density of the molten droplet is assumed to be constant. According to [38] the increase of the specific density of an Ti-6Al-4V alloy, the properties of which are very similar to those of pure titanium, could be estimated in the liquid state as about $10 \%$ per $1000 \mathrm{~K}$ decrease of temperature. In addition, about $10 \%$ weight increase can be expected during the saturation of titanium by nitrogen. However, other factors influencing the results (the density and diffusivity of gaseous nitrogen and the diffusivity of nitrogen in liquid $\mathrm{Ti}$ ) are changed much more significantly with temperature and consequently the change of density of the liquid will be ignored.

E) Local thermodynamic equilibrium is assumed to be reached at the interface between the gaseous and liquid phase. In particular, the temperature of the molten droplet has to be equal to the temperature of the gas in the vicinity of the gas-molten droplet interface.

F) Ideal gas and regular liquid solution approximations are used for the calculations of the density, pressure and temperature of gaseous nitrogen and the saturated pressure of titanium and nitrogen, which are in equilibrium with the molten droplet. The density of the gaseous fraction $n_{g}$ in close vicinity to a molten particle interface boundary can be calculated from Dalton's law of partial pressures:

$$
\begin{aligned}
& n_{g}=\frac{P_{0}}{k_{b} T}=n_{S, T i}+n_{N}= \\
& n_{S, T i}+n_{S, N}+n_{\text {ext }, N}
\end{aligned}
$$

where $P_{0}$ is the atmospheric pressure, $\mathrm{k}_{\mathrm{b}}$ is the Boltzmann constant, $n_{S, T i}$ and $n_{S, N}$ the saturated vapor pressure of evaporated titanium and nitrogen, respectively, $n_{N}$ is the total density of nitrogen and $n_{e x t, N}$ is the extra density of nitrogen caused by the evaporation of liquid nitrogen. It is accepted here, in agreement with [32], that $\mathrm{Ti}$ and $\mathrm{N}_{2}$ molecules are the main vaporization products. Consequently, $n_{\mathrm{S}, \mathrm{Ti}}$ and $n_{S, \mathrm{~N}}$ can be calculated in accepted approximations:

$$
\begin{aligned}
& n_{S, T i}=\frac{P_{0}(1-x)}{k_{b} T_{b, T i}} \exp \left(\frac{Q_{b, T i}}{R}\left(\frac{1}{T_{b}}-\frac{1}{T}\right)\right) \\
& n_{S, N}=\frac{P_{0} x}{k_{b} T_{b, T i}} \exp \left(\frac{Q_{b, T i}}{R}\left(\frac{1}{T_{b}}-\frac{1}{T}\right)\right)
\end{aligned}
$$

where $x$ is the atomic concentration of nitrogen in the Ti-N liquid solution, $Q_{b, T i}$ and $T_{b, T i}$ are the latent heat and boiling temperature of titanium.

The second Fick law describes nitrogen diffusion in the liquid state:

$$
\frac{\partial x}{\partial t}=D_{N, I}(T(t)) \frac{1}{r^{2}} \frac{\partial}{\partial r}\left(r^{2} \frac{\partial x}{\partial r}\right)
$$

Linear dependence of temperature on time $T=T_{0}-C R_{l s} \cdot t$ is assumed. At the interface boundaries at $r=R_{m d}$, a Fourier condition is employed, which suggests that the flux of nitrogen atoms through the interface boundary toward the liquid solution is proportional to the difference between the total atomic nitrogen concentration in the gaseous phase and the atomic 
concentration of saturated nitrogen vapor at the temperature of the molten particles:

$$
\begin{aligned}
& -D_{N, I}\left(\frac{\partial x}{\partial r}\right)_{r=R_{m d}}=h \frac{n_{g}}{n_{l}}\left(x_{N}-x_{S, N}\right)= \\
& h \frac{n_{g}}{n_{l}} x_{e x t, N}
\end{aligned}
$$

where $n_{g}$ and $n_{l}$ are the densities of the gaseous and liquid phases, respectively; $x_{\text {ext, } N}$ is the atomic concentration of extra nitrogen, which can be calculated from Eq. $6, h$ is the mass-transfer coefficient given by the Ranz-Marshall correlation [40]:

$$
S h=2+0.6 \operatorname{Re}^{\frac{1}{2}} S c^{\frac{1}{3}}
$$

According to the assumption $c$ ) in section iii, the Reynolds number $R e$ vanishes and the Sherwood number $S h$, representing the ratio of convective to diffusive mass transport, has to be equal to 2 (independently of the Schmidt number $S c$ ). As a result the mass transfer coefficient $h$ is equal to $2 D_{N, g} / r$. Reducing Eq. 9 one can obtain:

$$
\begin{aligned}
& -\left(\frac{\partial x}{\partial r}\right)_{r=R_{m d}}=\frac{D_{N, g}}{D_{N, l}} \frac{2}{r} \frac{P_{0}}{R T} \times \\
& \frac{\mu_{T i}}{\rho_{T i, l}} x_{e x t, N}=f(t)
\end{aligned}
$$

where $\mu_{T i}$ and $\rho_{T i, l} \approx 4 \mathrm{~g} / \mathrm{cm}^{3}$ are the atomic weight and specific density of liquid $\mathrm{Ti}$, respectively. $D_{N, g}$ is calculated in the gas-kinetic approximation:

$$
D_{N, g}=\frac{1}{3}\langle v\rangle \lambda
$$

where $\langle v\rangle=\sqrt{\frac{8 R T}{\pi 2 \mu_{N}}}$ is the average speed of the nitrogen molecules, $\lambda=\frac{k_{B} T}{\sqrt{2} \pi \delta^{2} P_{0}}$ is the mean free path of the molecules, and $\delta$ is the diameter of the nitrogen molecule. The motion of the interface boundary, which is caused by evaporation of titanium as well as absorption of nitrogen, may be important only just below the boiling point and is in first approximation ignored.

In the case of a constant coefficient of diffusion the problem can be reduced to a second initialboundary value problem for a linear second order parabolic equation. The solution of this equation is given by [60]:

$$
\begin{aligned}
& x(r, t)=\int_{0}^{R_{m d}} \mathrm{~g}(\xi) G(r, \xi, t) d \xi+ \\
& D_{N, l} \int_{0}^{t} f(\tau) G\left(r, R_{m d}, t-\tau\right) d \tau
\end{aligned}
$$

where $g(r)$ is the initial nitrogen distribution in the particle, $f(t)$ is the normalized flux (Eq. 11), and $G(r, \xi, t)$ has the following expression:

$$
\begin{aligned}
& G(r, \xi, t)=\frac{3 \xi^{2}}{R_{m d}^{3}}+\frac{2 \xi}{r R_{m d}} \sum_{n=1}^{\infty} \frac{\mu_{n}^{2}+1}{\mu_{n}^{2}} \times \\
& \sin \left(\frac{\mu_{n} r}{R_{m d}}\right) \sin \left(\frac{\mu_{n} \xi}{R_{m d}}\right) \exp \left(-\frac{D_{N, l}}{R_{m d}^{2}} \mu_{n}^{2} t\right)
\end{aligned}
$$

where $\mu_{n}$ are the roots of the transcendental equation $\operatorname{tg}(\mu)=\mu$. The diffusion coefficient of nitrogen in liquid Ti decreases practically linearly with decreasing temperature and varies by not more than a factor two between the boiling point and the peritectic temperature (Fig. 10). Therefore the use of an average value of this coefficient for numerical evaluations of Eq. 13 is reasonable.

The final saturation of liquid $\mathrm{Ti}$ by nitrogen depends on the initial nitrogen concentration $X_{N, 0}$, the initial temperature $T_{0}$ of the droplet and the cooling rate $C R_{l s}$. Before the splashing of the molten particles some absorption of nitrogen occurs during the spark discharge producing the molten bath of titanium on the surface of the granule at the place where the discharge propagates. The duration of the discharge is about $50 \mu \mathrm{s}$, the shape of the molten bath is a semisphere with a diameter of one to several hundred $\mu \mathrm{m}$. Evaluation of the initial nitrogen concentration as well as the dependence of the nitrogen content on the distance from the surface of such a molten bath after a $50 \mu$ s discharge can be obtained by means of Eqs. 13 and 14. Negligibly small (about 0.1 at.\%) dissolution of nitrogen in the superficial layer was found after $50 \mu$ s duration. Therefore the value of 0.1 at.\% of initial nitrogen concentration was used for further evaluations.

The effect of the initial temperature on the averaged value of the nitrogen concentration is significant. This is clearly seen on Fig. 12, where the dependence of the atomic concentration of nitrogen on a dimensionless radius is shown. The significant difference between the nitrogen concentration in the superficial layer and at the center of the particle is a particular feature of the nitrogen dissolution process in the liquid state. It should be noted that the plot in Fig. 12 remains invariant with respect to simultaneous changes of the diameter and cooling rate according to the relationship $C R_{l s} \times d^{2}=$ const, where $d$ is the diameter of the particle and the constant depends on the difference between the initial and final temperatures. Thus the relations between the cooling rate and the diameter of the particle are similar in the liquid and solid states.

\section{vii. Conjunction of the solutions and cooling rate in the mushy state}

The stage of liquid state cooling can be brought to an end if the nitrogen content on the interface boundary of particle will match the liquidus temperature. The processes of the nucleation of $\delta-\mathrm{TiN}_{x}$ can potentially begin after that. It should be noted that nucleation of $\delta$ - $\mathrm{TiN}_{x}$ has to start inevitably if the nitrogen content at the interface boundary of the particle will match the 

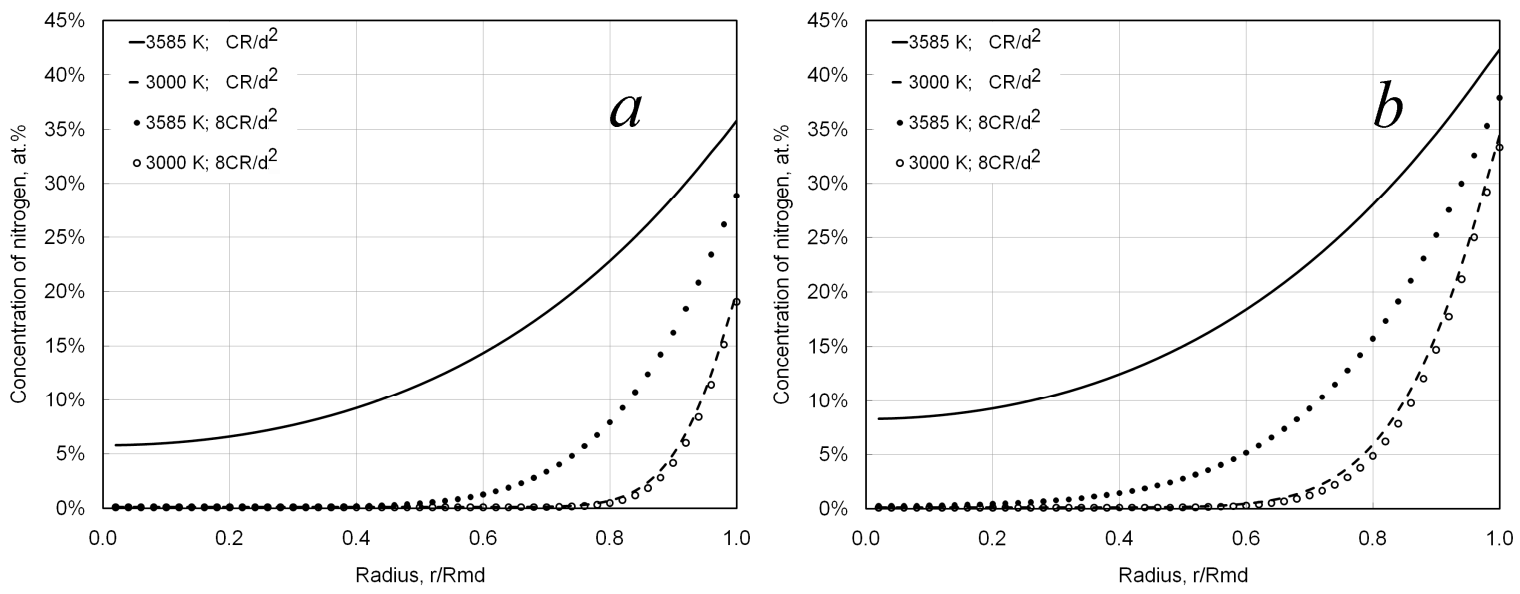

Fig. 12 Spatial nitrogen distribution in a molten droplet for different values of the initial temperature and cooling rate given in the invariant form according to Eq. $4 ; C R=2 \times 10^{7}\left[\mathrm{~K} / \mathrm{s}^{2} \mu \mathrm{m}^{2]}, d\right.$ is the diameter of the particle in $\mu \mathrm{m}$. The surface concentration of nitrogen corresponds to $a$ ) the liquidus, $b$ ) the solidus.
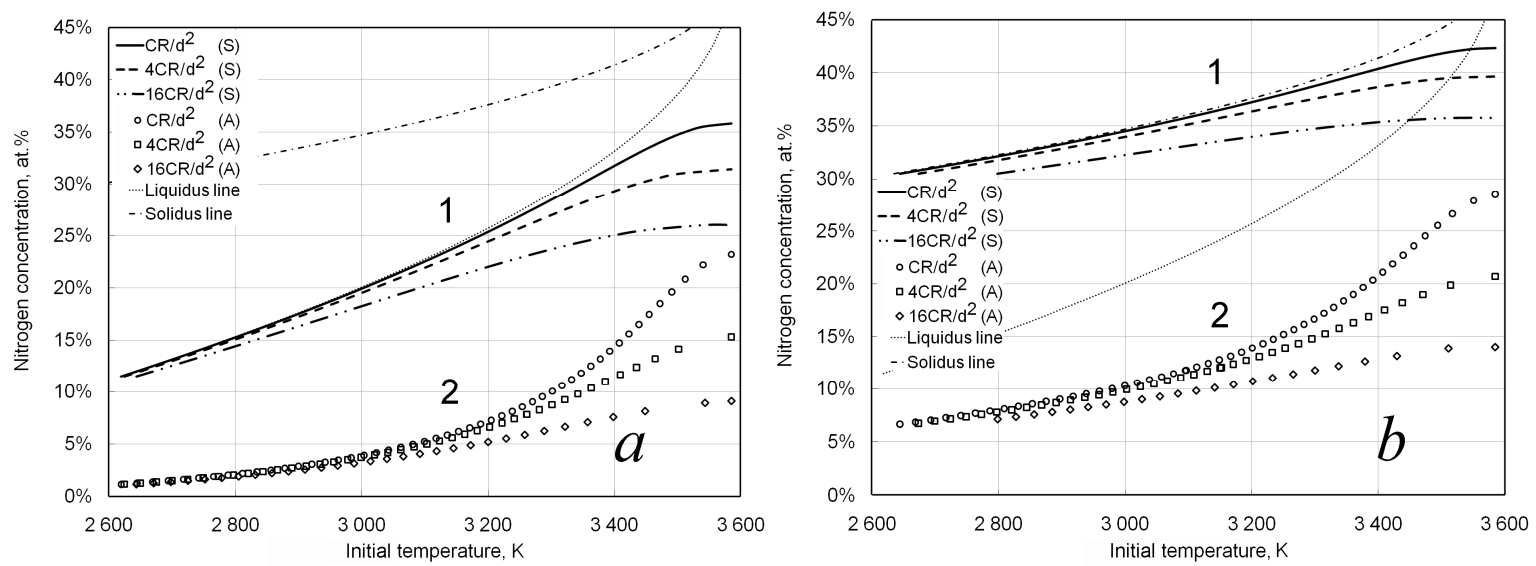

Fig. 13 Dependences of the surface (1, S in the legend) and average (2, A in the legend) nitrogen concentration on the initial temperature of the droplet: $a$ ) for "liquidus", $b$ ) for "solidus" final conditions on the surface. $C R$ is the cooling rate in the solid state given in invariant form as on Fig. 12.

solidus temperature. Hereinafter all results will be referred to the final conditions on the surface as "solidus" and "liquidus" respectively. The nitrogen content in the superficial layer of the particle and the average nitrogen content in the molten particles at the end of the liquid state cooling, depend on the cooling rate and the initial temperature of the droplets (Fig. 13).

The dependence on the cooling rate is significant only if the initial temperature of the droplet is in a temperature interval about $400 \mathrm{~K}$ below the boiling temperature of Ti. Another peculiarity is that there is an upper limit for the average nitrogen content in molten particles, which can be attained at a given cooling rate. According to Eq. 7 the saturated vapor pressure of evaporated titanium and nitrogen increases rapidly in the vicinity of the boiling temperature of $\mathrm{Ti}$. Although the diffusivity of nitrogen increases, the atomic concentration of extra nitrogen $x_{\text {ext }, N}$ diminishes rapidly with increasing temperature and the flux of nitrogen molecules from the gaseous shell to the molten particle is reduced (Eq. 9). The radial nitrogen distribution becomes more uniform. The nitrogen distributions obtained after cooling of the molten particle from different initial temperatures and at different cooling rates clearly illustrate this effect (Fig. 12).

The cooling history of spark erosion powders is very similar to those obtained by gas atomization or spraying methods. This statement finds an indirect confirmation in the microstructures of such powders, which are very similar (see microstructures in $[23,24])$. Usually the average cooling rate of gas atomized particles in the solid state is less than that in the liquid state, but the difference is not more than one order of magnitude. In turn the average cooling rate of particles in the mushy state is less than that in the solid state. We believe that the relationship between the cooling rate and diameter of spark eroded particles $C R \times d^{2}=$ const is valid for all stages of cooling, 
however, with different constants, which explains the mentioned relations between the cooling rates. Therefore all cooling rates will refer to the cooling rate $C R_{S S}$ in the solid state hereinafter.

The final nitrogen concentration is the sum of the contributions obtained during each of cooling stages:

$$
\begin{aligned}
& x_{N}=\Delta x_{N, L S}\left(C R_{L S}, T_{\max }\right)+ \\
& \Delta x_{N, M S}\left(C R_{M S}, x_{N, M S}\right)+\Delta x_{N, S S}
\end{aligned}
$$

where $\Delta x_{N, S S}=5.2$ at.\% (2.6 wt. \%) is the contribution of the solid state cooling stage, determined in section $\mathrm{v}$. The contribution of the mushy state cooling stage $\Delta x_{N, M S}\left(C R_{M S}, x_{N, M S}\right)$ can be found if the cooling rate in the mushy state $C R_{M S}$ and the final nitrogen concentration at the end of this stage $x_{N, M S}$ are known. The latter value ( 27.5 at.\%) was chosen assuming that the relation between the parts enriched and depleted with nitrogen (Fig. 6a) is inherited from the peritectic temperature and that the "lever rule" can be used during the peritectic solidification at least. The contribution of the liquid state cooling stage can be found if the cooling rate in the liquid state $C R_{L S}$ and the initial temperature $T_{\max }$ is known. Among the three values $C R_{L S}, T_{\max }$, and $C R_{M S}$, only two of them are independent because the final average nitrogen concentration after the first stage of cooling is the initial concentration for the second one. As it is seen from Fig. 12 a large nitrogen concentration in the superficial layer of particles initiates nucleation of $\delta$-TiN ${ }_{x}$ solid grains on the particle surface. Although the convective movement of these grains within the liquid droplets can continuously renew the surface of the droplets [23], the dominating effect is the shielding of the internal volume of particles from the external nitrogen by $\delta$-TiN $x$ solid grains. Thus the process of nitriding in the mushy state is more similar to solid-state nitriding than to the dissolution of nitrogen in the liquid state. Therefore Eq. 3 with $T_{\mathrm{f}}$ equal to the peritectic temperature was used for the calculation of the nitriding effect in this state.

Eq. 15 can be used to find $C R_{M S}$ as a function of the initial temperature of the particles $T_{\max }$ and the cooling rate in the liquid state $C R_{L S}$, provided that the cooling rate in the mushy state $C R_{M S}$ does not exceed that in the solid state (Fig. 14). For example, for a particle diameter of $10 \mu \mathrm{m}$ and a cooling rate in the solid state $C R_{\mathrm{SS}}=2 \times 10^{5} \mathrm{~K} / \mathrm{s}$, the maximum available cooling rate in the mushy state (denoted on Fig. 13 as $C R / d^{2}$ ) is no more than $2 \times 10^{5} \mathrm{~K} / \mathrm{s}$.

viii. Mechanism of the solidification and nucleation of the $\delta$-TiN $N_{x}$ phase in liquid particles

$C R_{M S}$ begins to depend significantly on the cooling rate in the liquid state $C R_{L S}$ only if the initial temperature of the droplets is above $\sim 3000 \mathrm{~K}$ (Fig. 14). This result is directly connected with the peculiarities of the nitriding process in the vicinity of the boiling point of $\mathrm{Ti}$ that were discussed above. Another surprising result is that the initial temperature, which satisfies Eq. 15, is much lower than the boiling temperature of $\mathrm{Ti}$, except in the case of very high cooling rates $C R_{L S}=16 C R_{S S}$. However, a large quantity of nanosized fraction requires a very high initial temperature of the particles. Virtually the initial temperature distribution can be very wide with a lower limit above the peritectic line $(2587 \mathrm{~K})$ and an upper limit around the boiling point $(3585 \mathrm{~K})$. For each $C R_{L S}$ only particles with the initial temperatures below a certain temperature can fulfill the restriction on cooling rates $C R_{M S}<C R_{S S}$ and Eq. 15 simultaneously $\left(e . g . \sim 3180 \mathrm{~K}\right.$ for $C R_{L S}=4 C R_{S S}=$ $4 C R / d^{2}(\mathrm{~S})$ on Fig. 14). In the case when the initial temperature is above this temperature, nitriding in the mushy state must be astonishingly fast to satisfy Eq. 15, so the cooling rate should be even higher than the cooling rate during the liquid stage. This is impossible because the cooling rate in the mushy state is governed not only by the heat transfer from the particles to the environment, but the liberation of crystallization heat and/or chemical reaction of the $\delta$ - $\mathrm{TiN}_{x}$ formation.

Two kinds of morphology of particles allow us to explain the above mentioned confusing result presuming two scenarios of nitriding in the mushy state. Multievent nucleation on the particle surface takes place due to the high nitrogen concentration on the surface of the molten particle (Fig. 12). $\delta-\mathrm{TiN}_{x}$ grains nucleated on the particle surface are drawn into droplets, where they liberate nitrogen in liquid titanium unsaturated with nitrogen. This process is governed by internal convection in the molten droplets and is the matter of a separate investigation. Hence nitrogen saturation in the mushy state is the result of a

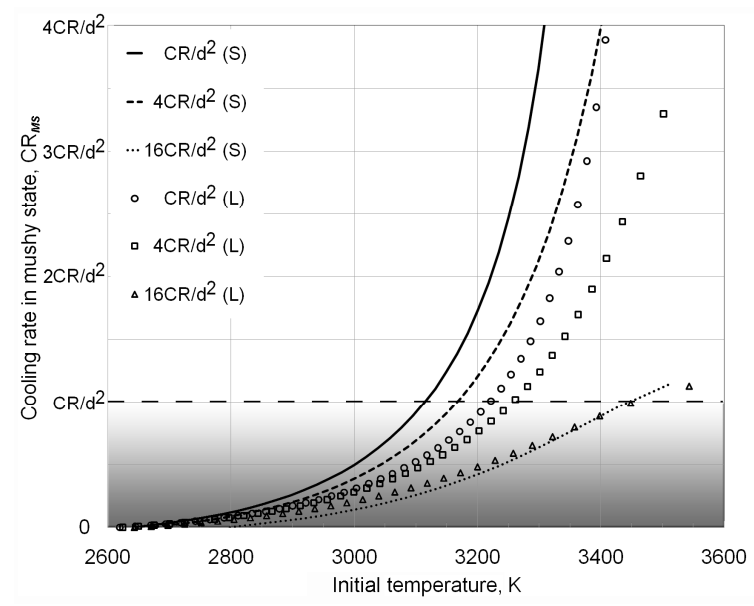

Fig. 14 Dependence of the cooling rate $C R_{M S}$ in the mushy state on the initial temperature for different cooling rates during liquid state cooling. (S) denotes the "solidus", (L) "liquidus" surface concentration conditions. Cooling rates are given in the invariant form $C R / d^{2}$ as on Figs. 12,13, where $C R$ is the cooling rate in the solid state. Gradient coloring illustrates that the feasibility of $C R_{M S}$ is the less the closer its value to the maximum available level $C R / d^{2}$ (dashed line). 
competition between the processes of external nitriding and denitridation of solid $\delta$ - $\operatorname{TiN}_{x}$. In the case of a low initial temperature the difference between the nitrogen concentration inside the particle and on its surface is large (Fig. 12). The average nitrogen content after finishing liquid state cooling is lower than that on the liquidus at a given temperature and far from thermodynamical equilibrium (Fig. 13). If the particle surface freezes sporadically, first the $\delta$-TiN $x$ shell prevents the diffusion of $\mathrm{N}$ through the surface and causes depletion of nitrogen in the $\delta$-phase grains inside the droplets and the formation of $\alpha-\mathrm{Ti}(\mathrm{N})$. The different specific volume of the liquid and the solid phases [38] causes the creation of voids during the peritectic solidification. Regular globular, oblong formations inside the pores are typical for a peritectic microstructure. Their sizes and regularity indicate that the cooling rate is low enough at this stage to ensure a thermodynamical equilibrium process.

In the case of high initial temperatures, a more uniform nitrogen distribution (Fig. 12) promotes nucleation of $\delta-\mathrm{TiN}_{x}$ in the entire particle volume upon cooling in the mushy state. The lower viscosity of liquid $\mathrm{Ti}$ and hence faster internal movements of the $\delta-\mathrm{TiN}_{x}$ grains renew continuously the surface of the particles with liquid $\mathrm{Ti}(\mathrm{N})$ upon cooling. With decreasing temperature and lowering of the nitrogen solubility in both liquid $\mathrm{Ti}$ and $\delta$ - $\mathrm{TiN}_{x}$, the solidification produces typical a "lava" relief on the particle surface with finest separate island-drops of smooth irregular shape with small holes, through which excess nitrogen gas can leave the particle.

Only the cooling rate in the solid state $C R_{S S}$ given by Eq. 4 can be considered as more or less accurate. The evaluation of the cooling rates during the liquid state stage gives the lower limits of the cooling rate, namely $C R_{L S} \approx(1 \div 10) C R_{S S}$. Such processes like black body emission, internal and external convection, can only increase the cooling rate in the liquid state. A feasible interval of the cooling rate in the mushy state is much more uncertain: $C R_{M S}<C R_{S S}$.

\section{Conclusions}

1) Titanium powder particles from several decades of microns down to 10 nanometers were produced by the spark erosion method in liquid nitrogen. As-processed powder particles with typical sizes between 1 and 50 microns have a shape that is not perfectly spherical. Many of the micron-sized particles have voids inside, which have an irregular shape. The surface of the $\mathrm{Ti}$ powder particles has irregular or uneven structure, in opposition to the well arranged bubble-like structure of the inner surface of the pores inside the particles.

2) The total nitrogen content in the powder determined from XRD data was $12.4 \pm 0.2$ wt. $\%$ or $32.6 \pm 0.4$ at. $\%$. The micron-sized particles of the powder are chemically inhomogeneous. A cellular structure with nitrogen-rich areas of about several microns, separated by finer boundaries depleted by nitrogen was found in the particles.

3) The powder contains about $85 \mathrm{wt} . \%$ of the $\delta$-TiN nitride (osbornite, $\mathrm{Fm}-3 \mathrm{~m}$ ), $10 \mathrm{wt} . \%$ of the nitrogen solution in titanium $\alpha-\mathrm{Ti}(\mathrm{N})\left(P 6_{3} / m m c\right)$ and no more than 4 wt. $\%$ of $\alpha$ - and $\beta$-Ti. The amounts of the different fractions in the powder is the following: the mechanical fraction- $3 \div 4 \mathrm{wt} . \%$; the micron-sized particles formed from the liquid state $-77 \pm 10 \mathrm{wt} . \%$; the nanosized particles formed from the vapor state $19 \pm 10$ wt. $\%$.

4) The particles with sizes between 10 and $100 \mathrm{~nm}$ are equiatomic $\delta$-TiN $\mathrm{T}_{x}$ nitride. They have spherical shape, although somewhere cuboids appear. Some of the ultrafine particles can be TiO oxide.

5) The model developed for the solidification of $\mathrm{Ti}$ liquid droplets in liquid nitrogen assumes rapid quenching of the particles in cold gas, powder velocities close to zero, and multiple nucleation of the solid phase on the surface of the liquid droplets. It ignores internal (inside the molten and freezing particles) and external (in the surrounding gaseous shell) convection. This model considers three stages of cooling, namely, during the liquid, mushy and solid state.

6) The evaluated temperatures of the molten droplets that are reached during the spark discharge, are not lower than $2587 \mathrm{~K}$ (peritectic temperature) and not higher than the boiling point of titanium.

7) The average cooling rates $C R_{X S}[\mathrm{~K} / \mathrm{s}]$ have been evaluated for each of the stages from nitrogen dissolution and nitriding kinetics. It can be represented in an invariant form $C R_{X S} \times d^{2}=$ const, where $d$ - diameter of a particle $[\mu \mathrm{m}]$ and the constant depends on the stage of cooling. For the solid state cooling stage this relation is manifested as $C R_{S S} \times d^{2}=$ $2 \times 10^{7}$; for the other stages the following relationships have to be fulfilled: $C R_{L S} \approx(1 \div 10) C R_{S S}$ and $C R_{M S}<C R_{S S}$.

8) The competition between the processes of external nitriding and denitridation of solid $\delta$ - $\mathrm{TiN}_{x}$ grains inside the particles, as well as the lowering of the nitrogen solubility in liquid $\mathrm{Ti}$ and $\delta$-TiN $\mathrm{T}_{x}$, causes nitrogen saturation in the mushy state and sets the final element distribution in the particles. The different specific volumes of solid $\delta-\mathrm{TiN}_{x}$ nitride and liquid titanium promote the creation of pores during freezing of the mushy zone.

\section{Acknowledgements}

The authors are grateful to the CNRS (PICS-3717, STCU (\#3520, \#3144)) and ECONET for projects supporting this work. They also thank Tokyo Boeki CIS LTD for having given them the opportunity to carry out careful scanning microscopy studies. 


\section{References}

[1] G.E. Monastyrsky, P.A. Yakovenko, V.I. Kolomytsev, Yu.N. Koval, A.A. Shcherba, R. Portier, Mater. Sci. Eng. A 481-482 (2008) 643-646.

[2] G.E. Monastyrsky, V.V. Odnosum, V.I. Kolomitsev, Yu.N. Koval, P. Ochin, R. Portier, A.A. Shcherba, S.N. Zaharchenko, Metallofiz. Nov. Tekhnol. 30 (2008) 761-772.

[3] J. Carrey, H.B. Radousky, A.E. Berkowitz, J. Appl. Phys. 95 (2004) 823.

[4] A.E. Berkowitz, H. Harper, D.J. Smith, Hao Hu, Qian Jiang, V.C. Solomon, H.B. Radousky, Appl. Phys. Lett. 85(6) (2004) 940-942.

[5] A.E. Berkowitz, J.D. Livingston, J.L. Walter, J. Appl. Phys. 55 (1984) 2106.

[6] A.E. Berkowitz, M.F. Hansen, F.T. Parker, K.S. Vecchio, F.E. Spada, E.J. Lavernia, R. Rodriguez, J. Magn. Magn. Mater. 254-255 (2003) 1.

[7] H. Wan, A.E. Berkowitz, Scr. Metall. Mater. 32 (1995) 1827.

[8] Y.J. Tang, F.T. Parker, H. Harper, A.E. Berkowitz, Q. Jiang, D.J. Smith, M. Brand, F. Wang, IEEE Trans. Magn. 40 (2004) 2002.

[9] M.S. Hsu, M.A. Meyers, A. Berkowitz, Scr. Metall. Mater. 32 (1995) 805.

[10] V. Solomon, D.J. Smith, Yun Jun Tang, A.E. Berkowitz, J. Appl. Phys. 95 (2004) 6954.

[11] J.I. Hong, V.C. Solomon, D.J. Smith, F.T. Parker, E.M. Summers, A.E. Berkowitz, Appl. Phys. Lett. 89 (2006) 146.

[12] G.E. Monastyrsky, A.P. Shpak, Yu.N. Koval, R.Ya. Musienko, Metallofiz. Nov. Tekhnol. 6(25) (2003) 803-816.

[13] G.E. Monastyrsky, Yu.N. Koval, A.P. Shpak, R.Ya. Musienko, V.I. Kolomytsev, A.A. Shcherba, S.N. Zaharchenko, P.G. Jakovenko, Poroshk. Metall. 5/6 (2007) 3-15.

[14] G.E. Monastyrsky, V.I. Kolomytsev, Yu.N. Koval, A.A. Shcherba, S.M. Zaharchenko, R. Portier, Nanosist. Nanomater. Nanotekhn. 5(2) (2007) 54-60.

[15] O.M. Ivanova, M.I. Danylenko, G.E. Monastyrsky, V.I. Kolomytsev, Yu.N. Koval, A.A. Shcherba, S.M. Zaharchenko, R. Portier, Metallofiz. Nov. Tekhnol. 31(5) (2009) 603-614.

[16] G.M. Monastyrsky, P. Ochin, G.Y. Wang, V.I. Kolomytsev, Yu.N. Koval, A.V. Gilchuk, V.O. Tinkov, A.A. Shcherba, S.M. Zaharchenko, Chem. Met. Alloys (in press).

[17] A.A. Shcherba, A.D. Podoltsev, I.N. Kucheryavaya, Tekhn. Elektrodin. 6 (2004) 4-17.

[18] O. Schneeweiss, Y. Jirásková, P. Řepa, Proc. Natl. Conf. Nano'02, Brno, Czech Republic, 2002, pp. 105-107.

[19] Y. Jirásková, S. Havlícek, O. Schneeweiss, V. Peřina, C. Blawert, J. Magn. Magn. Mater. 234 (2001) 477-488.
[20] E.D. Cabanillas, M. López, E.E. Pasqualini, D.J. Cirilo Lombardo, J. Nucl. Mater. 324 (2004) 1-5.

[21] A.E. Berkowitz, J.L. Walter, Mater. Sci. Eng. 55 (1982) 275.

[22] G.Ya. Kolbasov, A.I. Ustinov, A.A. Shcherba, A.Ye. Perekos, M.O. Danilov, N.V. Vyunova, S.N. Zakharchenko, G. Hossbah, J. Power Sources 150 (2005) 276-281.

[23] A. Denoirjean, P. Lefort, P. Fauchais, Phys. Chem. Chem. Phys. 5 (2003) 5133-5138.

[24] C. Marchand, A. Maître, A. Grimaud, A. Denoirjean, P. Lefort, Surf. Coat. Technol. 201 (2006) 1988-1994.

[25] V.V. Dabhade, T.R.R. Mohan, P. Ramakrishnan, J. Alloys Compd. 453(1-2) (2008) 215-221.

[26] Chan Uk Bang, Yong Cheol Hong, Han Sup Uhm, Surf. Coat. Technol. 201 (2007) 50075011.

[27] Y. Chen, A.W. Castleman, Jr., J. Chem. Phys. 98(I) (1993) 231-235.

[28] S. Nagakura, T. Kusunoki, F. Kakimoto, Y. Hirotsu, J. Appl. Crystallogr. 8 (1975) 65-66.

[29] J.P. Bars, D. David, E. Etchessahar, J. Debuigne, Metall. Trans. A 14 (1983) 1537-1543.

[30] J.D. Houmes, H.-C. zur Loye, J. Solid State Chem. 130 (1997) 266-271.

[31] G. Vedovato, A. Zambon, E. Ramous, Mater. Sci. Eng. A 304-306 (2001) 235-239.

[32] S. Jonsson, Z. Metallkd. 87(9) (1996) 691-702.

[33] K.J. Zeng, R. Schmid-Fetzer, Z. Metallkd. 87(7) (1996) 540-554.

[34] W. Lengauer, P. Ettmayer, Rev. Chim. Miner. 24 (1987) 707-713.

[35] W. Lengauer, P. Ettmayer, Mater. Sci. Eng. A 105/106 (1988) 257-263.

[36] C. Ponticaud, A. Guillou, P. Lefort, Phys. Chem. Chem. Phys. 2 (2000) 1709-1715.

[37] I.M. Pohrelyuk, Mater. Sci. 35(1) (1999) 66-74.

[38] M. Boivineau, C. Cagran, D. Doytier, V. Eyraud, M.-H. Nadal, B. Wilthan, G. Pottlacher, Int. J. Thermophys. 27(2) (2006) 507-529.

[39] A. Pasturel, Mater. Res. Soc. Symp. 186 (1990) 47-99.

[40] W.E. Ranz, W.R. Marshall, Chem. Eng. Proc. 48 (1952) 141.

[41] A. Kajinic, http://www.calphad.com/titaniumnitrogen.html

[42] H.A. Wriedt, J.L. Murray, In: T. Massalski (Ed.), Binary Alloy Phase Diagrams, Vol. 2, ASM, Metals Park, OH, 1986, 1655 p.

[43] V.D. Repkin, G.V. Kartuhov, A.A. Kornilov, V.V. Bespalov, Metallograficheskie Protsessy v Khimii i Metallurgii, Nauka, Novosibirsk, 1971, 320-330.

[44] Yu.V. Levinskii, Izv. Akad. Nauk SSSR, Neorg. Mater. 4(12) (1968) 2068-2071.

[45] A.Ya. Eremeev, Yu.M. Ivanov, A.S. Panov, Izv. Akad. Nauk SSSR, Met. 4 (1969) 182-186.

[46] J.P. Bars, E. Etchesahur, J. Debuigne, J. LessCommon Met. 52(1) (1977) 51-76. 
[47] F.W. Wood, O.G. Paasche, Thin Solid Films 40 (1977) 131-137.

[48] E. Fromm, E. Gebhardt, Proc. Dimeta-82, Tihany, Hungary, 1982, pp. 229-230.

[49] R.J. Wasilewski, H. Kehl, J. Inst. Met. 83 (1955) 94.

[50] A. Meyer, J. Horbach, O. Heinen, D. HollandMoritz, T. Unruh, Defect Diffus. Forum 289-292 (2009) 609-614.

[51] I. Takamichi, G. Roderick, T. Nagendra, Metall. Mater. Trans. B 37 (2006) 559.

[52] S.J. Savage, E.C. Harper Jr., US Patent \#4731515, 1988.

[53] M. Tabuchi, Y. Kaneko, H. Iwasaki, J. Ceram. Soc. Jpn. 98 (1990) 1296-1301.

[54] T. Sato, K. Usuki, A. Okuwaki, Y. Goto, J. Mater. Sci. 27 (1992) 3879-3882.
[55] T. Sato, S. Yasuda, K. Usuki, T. Yoshioka, A. Okuwaki, J. Mater. Sci. 31 (1996) 2495-2499.

[56] G. Caglioti, A. Paoletti, F.P. Ricci, Nucl. Instrum. 3 (1958) 223-228.

[57] W. Lengauer, J. Alloys Compd. 186(2), (1992) 293-307.

[58] J.Å. Persson, Handbook for Kjeldahl Digestion, Höganäs, Sweden, 1995.

[59] A.H. Gillieson, In: N.E. Promisel (Ed.), The Science and Technology of Tungsten, Tantalum, Molybdenum, Niobium and Their Alloys, AGARDograph 82, Pergamon Press, 1964, pp. 381-393.

[60] A.D. Poljanin, Spravochnik po Lineynym Uravneniyam Matematicheskoy Fiziki, FizikoMatematicheskaya Literatura, Moskva, 2001, p. 79. 